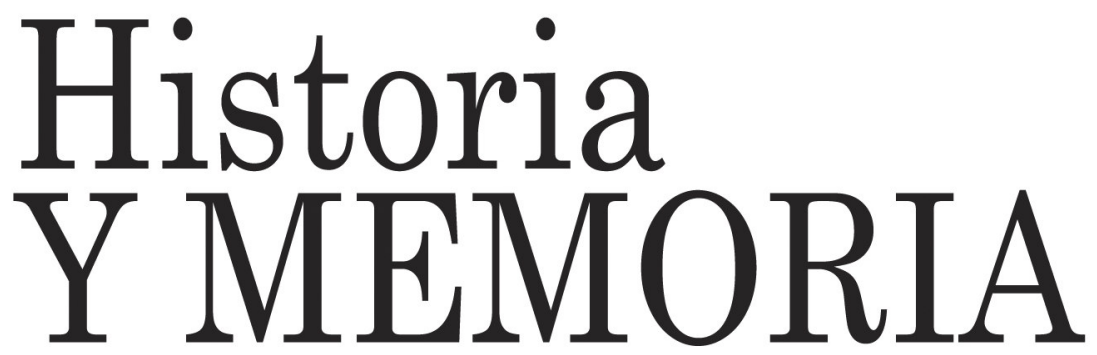

ISSN: 2027-5137

Julio - Diciembre, Año 2013 - Tunja, Colombia

Patriotismo o universalismo proletario. E1 lugar del mundo en el obrerismo y el socialismo colombiano, 1904-1930

Isidro Vanegas Useche Páginas: 269 - 332

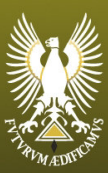




\title{
Patriotismo o universalismo proletario. El lugar del mundo en el obrerismo y el socialismo colombiano, 1904-1930
}

\author{
Isidro Vanegas Useche ${ }^{1}$ \\ Universidad Pedagógica y Tecnológica de Colombia
}

Recepción: 08/08/2013

Evaluación: 30/08/2013

Aceptación: 17/10/2013

Artículo de Investigación Científica.

\section{Resumen}

¿Cuál es el rol de los agentes y dinámicas externas en la introducción de una corriente política en un país como Colombia? ¿Una intensa conexión con el exterior es signo de una fructífera modernización de los discursos y las prácticas políticas? Este texto indaga acerca de la manera como los grupos obreristas y socialistas de comienzos del siglo XX se situaron ante el mundo, esto es, cómo definieron la patria a la que aspiraban y qué lugar le dieron en el conjunto universal. Se muestra cómo en un primer momento los activistas políticos ligados al mundo popular optaron por una baja intensidad de sus relaciones directas con Europa y Estados Unidos, afirmando su búsqueda de mayor igualdad dentro de una vindicación de la patria nacional. En una etapa posterior,

\footnotetext{
1 Doctor en Historia, Universidad de París I. Magíster en Historia Contemporánea. Profesor de la Escuela de Ciencias Sociales y del Doctorado en Historia, Universidad Pedagógica y Tecnológica de Colombia. Integrante Grupo de Investigación Asociación Centro de Estudios Regionales. isivanegas@yahoo.com
} 
los socialistas rechazarán la nación, ilusionados por un universalismo comunista que los puso en un amplio contacto con lo que llegó a considerarse como la matriz de una nueva humanidad, sólo que al precio de enajenarse la simpatía de quienes pretendían representar.

Palabras clave: socialismo, democracia, Colombia, nación, universalismo comunista.

\title{
Patriotism or proletarian universalism. The place of the world in Colombian workerism and socialism, 1904-1930
}

\begin{abstract}
What is the role of external agents and dynamics in the introduction of a political movement in a country like Colombia? Can an intense connection with the outside world be read as a sign of the successful modernization of political discourses and practices? This article inquires into the position of workerist and socialist groups in the beginning of the XX century with respect to the outside world; that is, how they defined the Nation to which they aspired, and what place they gave to the universe as larger context. Findings show that in a first stage, political activists of the working classes maintained scarce relations with Europe and United States, reaffirming their search for greater equality as part of the vindication of the Nation. In a further stage, however, socialists rejected the Nation, building their hopes in the direction of a communist universalism, which put them into extended contact with what was considered the matrix for a new humanity; at the cost of alienating the sympathy of the people they intended to represent.
\end{abstract}


Key words: socialism, democracy, Colombia, nation, communist universalism

\section{Patriotisme ou universalisme prolétaire. La place du monde dans l' ouvriérisme et le socialisme colombien, 1904-1930}

\section{Résumé}

Quel rôle ont joué les agents et les impulsions externes dans l'avènement d'une certaine courant politique en Colombie, ou dans n'importe quelle nation? Une connexion intense avec l'étranger est-elle le signe d'une modernisation féconde des discours et des pratiques politiques? Ce texte enquête sur la manière dont les groupes ouvriéristes et socialistes du début du $\mathrm{XX}^{\mathrm{e}}$ siècle se sont situés face au monde: comment ils ont défini la patrie à laquelle ils aspiraient et quelle place ont-ils accordé a celle-ci dans l'ensemble universel. L'article veut montrer comment dans un premier temps, par rapport à l' Europe et les États-Unis, les activistes politiques liés au monde populaire ont choisi un type de relations directes de faible intensité, en affirmant leur quête d'une plus grande égalité à l'intérieur d'une justification de la patrie nationale. Dans une étape postérieure, les socialistes repousseront la nation, séduits par l'universalisme communiste qui leur a donnés un contact étendu avec ce que l'on a considéré comme la source d'une nouvelle humanité. En contrepartie, ils ont perdu la sympathie de ceux qu'ils essayaient de représenter.

Mots clés: Socialisme, démocratie, Colombie, nation, universalisme communiste. 


\section{Introducción}

Desde el nacimiento del régimen democrático en Colombia, con la Revolución Neogranadina de la década de 1810, los actores de la escena política han intervenido debiendo situarse no sólo respecto a la sociedad colombiana y sus encrucijadas sino también respecto a las eventualidades que abre o a que incita el mundo. Liberales y conservadores, e incluso antes, cuando esos partidos carecían de existencia formal, no dejaron de ponerse en relación con los sucesos, las ideas, las sensibilidades, las prácticas políticas más sobresalientes en los países europeos y americanos. Esto significó, entre otras cosas, que a Colombia llegaran individuos deseosos de ejercer alguna actividad política y que algunos colombianos - muchos menos en cantidad - fueran a otros países a ejercer actividades semejantes.

Este texto indaga acerca de la manera como los grupos obreristas y socialistas de comienzos del siglo $\mathrm{XX}$ se situaron ante el mundo, esto es, cómo definieron la patria a la que aspiraban y qué lugar le dieron en el conjunto universal. Un aspecto de esa indagación consiste en describir los vínculos internacionales tejidos por esos grupos, mostrando tanto el tipo de encajamiento que hicieron de los nuevos referentes en las tradiciones políticas existentes como los resultados de aquellos vínculos sobre sus concepciones y prácticas.

\section{Un amor sin locura hacia la patria}

La separación del departamento de Panamá en 1903 hizo creer que la nación yacía en una crisis profunda, sentimiento que fue particularmente visible entre los activistas políticos ligados al mundo del trabajo, quienes 
culparon a los conflictos partidistas de todos los males que postraban a la patria. Aquel sentimiento convergió con las penurias sobrevenidas tras la guerra de los mil días para hacer renacer las demandas proteccionistas de los artesanos de varias ciudades, los cuales trataron de organizarse gremialmente para enfrentar lo que consideraban una "extraordinaria introducción de artículos manufacturados" como calzado, vestidos y muebles. ${ }^{2}$ Fruto de esa inquietud surgió en Bogotá a mediados de 1904 la Unión de Industriales y Obreros, organización pionera en su pretensión gremialista, ya no simplemente de tipo mutual, cuya primera acción fue solicitar al gobierno el alza de los derechos de importación. Uno de sus impulsores, el liberal Juan Ignacio Gálvez, expresó ideas ampliamente compartidas por entonces respecto a la situación de los trabajadores colombianos en contraste con los de Europa. Gálvez manifestó que los primeros vivían con "relativa comodidad", no se morían de hambre, eran amparados por leyes que les permitía organizarse, y no tenían que luchar con la competencia de las máquinas, la cual en Europa había dado origen a la "célebre Internacional de obreros y a los Trades Unions". ${ }^{3}$ Gálvez concluía que si en Europa las sociedades obreras se justificaban, no había ninguna razón para copiar en Colombia sus fines y sus medios. Menos lugar había para simpatizar con el socialismo, según lo expresó un líder emblemático de la Unión, el legendario activista José Leocadio Camacho, quien respondió a aquellos que calificaban de socialista a la Unión diciendo que esas críticas tal vez se debieran a que siendo ella una causa noble, los maliciosos le atribuían "distintos fines de los

\footnotetext{
2 "Los obreros de Popayán", abril de 1904, en Juan Ignacio Gálvez, Dos conferencias. Organización obrera en Colombia, (Quito: Casa Editorial de J. I. Gálvez, 1912), 57.

${ }^{3}$ Juan Ignacio Gálvez, Dos Conferencias, ... 79-83.
} 
que ella se proponía, apellidándola socialista, como si el socialismo hubiese de ser lo que tiende al bien, y no al perjuicio de los demás". ${ }^{4}$ Camacho expresaba así la idea predominante acerca del socialismo, que lo veía como un estigma, concepción imperante también entre los activistas políticos ligados a los artesanos, y probablemente entre los artesanos mismos.

Aquella tentativa de organización de los artesanos sólo pudo persistir hasta finales de 1904. En ese momento el presidente Rafael Reyes tomó en cuenta su demanda de elevación de los aranceles pero simultáneamente procedió a impedir que se organizaran, amenazando a los gestores y colocando en puestos diplomáticos a dos de los más notables jefes liberales asentados en Bogotá y que tenían un anclaje importante en los asuntos laborales: Juan Ignacio Gálvez y Rafael Uribe Uribe. Este popular caudillo había manifestado, en octubre de 1904, que el liberalismo debía comprometerse con una mayor intervención del Estado en la economía, con lo cual consumaba la revisión de ideas veneradas por su partido durante más de cinco décadas. Y aunque el voluble Uribe parece haberse desentendido de su socialismo de Estado poco tiempo después, puede ser tenido por uno de los precursores de la valorización del término socialismo. ${ }^{5}$ Pero Reyes envió a Uribe a una misión diplomática al Cono sur, impidió las actividades de la Unión de Industriales y Obreros y encarceló a varios líderes obreristas. Habiendo impuesto una mordaza general a la expresión política,

\footnotetext{
${ }^{4}$ Juan Ignacio Gálvez, Dos Conferencias,...70. Sobre Camacho, véase David Sowell, "José Leocadio Camacho: Artisan, Editor, and Political Activist", en The Human Tradition in Latin America: The Nineteenth Century, (Wilmington - Delaware: Scholarly Resources, 1989), 269-279.

${ }^{5}$ Rafael Uribe Uribe, Socialismo de Estado. Conferencia leída por el General Uribe Uribe, en el Teatro Municipal de Bogotá, el 23 de octubre de 1904, (Bogotá: Ediciones Boza, s.f.).
} 
incluso la de sus propios copartidarios conservadores, su caída (marzo de 1909) fue festejada ampliamente, y dio paso a un florecimiento de la vida política. Diversos activistas iniciaron por entonces esfuerzos organizativos anclados en el mundo del trabajo pero abiertos al contacto partidista, que se añadieron a los de tipo mutual o estrictamente gremial que habían sido los únicos existentes en el siglo XIX, mientras que algunos pocos individuos publicaron periódicos en los que ellos se reconocieron como socialistas, comunistas o anarquistas. El socialismo, y mucho más el anarquismo, sin embargo, continuaban siendo censurados comúnmente por los activistas consagrados a dar algún tipo de expresión al mundo del trabajo. El destacado activista Pablo Emilio Mancera, por ejemplo, expresó en 1910 una concepción del socialismo que lo veía como uno de los males que aquejaba a los trabajadores: "La falta de estímulo a la clase obrera origina el socialismo, los crímenes, el alcoholismo, la locura y mil calamidades más que el Gobierno y las personas pudientes pueden remediar en parte, protegiendo las industrias nacionales, procurando ocupación al trabajador y retribuyendo mejor su salario". ${ }^{6}$

Paralelamente a manifestaciones como esta, algunos intermediarios políticos ligados a los sectores populares expresaban novedosas simpatías hacia el socialismo en varias regiones del país. El Símbolo, efímero periódico aparecido en Cartagena a comienzos de 1910, fue quizás uno de los primeros en vindicar públicamente aquella doctrina, viéndola como una ciencia política adaptable a todas las naciones - “desde Inglaterra que es el país más fuerte y próspero, hasta Colombia que es el más débil y degenerado" - y como tal capaz de desarrollar en mayor

\footnotetext{
${ }^{6}$ Artículo publicado inicialmente en La Libertad, y reproducido en "El artesano", Álbum Rojo, No. 12, enero 29 de 1910, Santander de Quilichao, p. 2.
} 
grado la inteligencia, la moralidad y el bienestar social. ${ }^{7}$ A mediados de ese mismo año en Barranquilla fue proclamada la necesidad de crear un "partido socialista" a nivel local, y en Bogotá Juan Francisco Moncaleano, desde su periódico El Ravachol, instó a los artesanos a adoptar el socialismo como su causa. ${ }^{8}$ No obstante, los discursos radicales encontraron en un primer momento grandes dificultades para hacerse un espacio significativo, cuando menos entre los intermediarios políticos de Bogotá, como lo ilustra el caso de Juan Francisco Moncaleano. Coronel liberal de las guerras civiles, él hizo un tránsito vertiginoso de un discurso liberal teñido fuertemente de nacionalismo a un discurso socialista, dándole a su periódico, Ravachol, un tono anticlerical y pugnaz. Moncaleano llamó a los trabajadores a abrazar el credo socialista pero su prédica no levantó adhesiones y, presionado por el gobierno que lo encarceló en varias ocasiones, tuvo que alejarse del país. Viajó entonces a Cuba y luego a México, donde pese a vivir sólo un breve periodo - fue de nuevo expulsado - tuvo una destacada participación en las actividades anarquistas. ${ }^{9}$

Mientras los discursos socialistas tenían tales dificultades para arraigar, desde los partidos políticos se desplegaron iniciativas orientadas a captarse un apoyo de tipo gremial entre algunos grupos de población. En Bogotá se aludió en 1910 a la creación de un Partido Obrero, proyecto que mostraba los anhelos de ciertos líderes políticos ligados al artesanado de desprenderse de los partidos políticos existentes, o al menos, de darle a la cuestión laboral un estatus más relevante en el seno

\footnotetext{
7 "Palique. Colombia y el socialismo", El Símbolo, No. 2, marzo 14 de 1910, Cartagena, p. 1.

8 "Partido socialista", El Renacimiento, julio 7 de 1910, Barranquilla; "El socialismo", El Ravachol, No. 4, julio 17 de 1910, Bogotá, p. 2.

9 "Socialismo. La redención del obrero", Ravachol, No. 13, septiembre 18 de 1910, Bogotá, p. 3; John Hart, El anarquismo y la clase obrera mexicana: 1860-1931, (México: Siglo XXI Editores, 1980), 150-168.
} 
del liberalismo y el republicanismo. Así mismo fueron creadas la Unión Nacional de Industriales y Obreros (1909) y la Unión Obrera Colombiana (1913), ambas en Bogotá, en las que variados tipos de trabajadores se juntaron con activistas políticos que eran ellos mismos trabajadores independientes. Estos ayudaron a dinamizar considerablemente el intercambio de ideas además de incentivar nuevos reclamos y nuevas formas de movilización de las organizaciones populares. Su prédica fue logrando, si no conquistar masivamente a los trabajadores para el socialismo o el anarquismo, al menos atraerlos a ciertas reivindicaciones laborales y sociales novedosas. De esta manera se vio confrontada la percepción estigmatizante del socialismo, que había sido la única existente socialmente hasta entonces.

Quienes veían valores positivos en el socialismo sencillamente asimilaban dicha corriente política a la causa de los obreros, de manera que partido socialista y partido obrero les resultaban nombres indistintamente adecuados para designar una eventual organización política ajena a los partidos. En esa acepción, el socialismo solía designar un conjunto heterogéneo y acotado de reivindicaciones laborales (salvaguarda del empleo, protección arancelaria, mantenimiento de la capacidad adquisitiva del salario, respeto por parte de los patronos, seguridad laboral) y de bienestar (vivienda, instrucción, higiene), antes que un universo de aspiraciones políticas susceptibles de ser satisfechas por el Estado. Este lo consideraban un factor de mejoramiento, pero en este sentido le daban una importancia quizá semejante a las iniciativas gremiales de ahorro y protección mutua y a la austeridad y la instrucción que deberían desarrollar los individuos. El socialismo concebido así no contenía muchos elementos inéditos, pues proponía ideales de libertad, igualdad y fraternidad que desde hacía mucho tiempo encontraban adalides dentro de la república, y que en la década de 1910 fueron expresados continuamente en los discursos y las ceremonias obreristas, como el 
primero de mayo, que comenzó a celebrarse públicamente desde $1914 .{ }^{10}$

La inmensa mayoría de aquellos activistas obreristas no tuvo un contacto personal con el exterior, en el sentido que no viajaron a otros países, contrastando su situación con la posibilidad que se abrió en las primeras décadas del siglo XX a grupos sociales de alguna amplitud, ya no sólo las élites, ${ }^{11}$ para observar directamente algún país distinto a Colombia. Los pocos casos de activistas que tuvieron tal ocasión fueron consignados de manera encomiástica en los periódicos obreristas, como que esa actividad los habilitaba para servir mejor la causa de los trabajadores. El liberal Vicente Olarte Camacho, abogado vinculado a la Unión Nacional de Industriales y Obreros, viajó en 1912 a Europa, donde prestó atención a las organizaciones obreras, algunas de las cuales (la "Confederación obrera internacional de Suiza" particularmente) lo nombraron su corresponsal en el país. ${ }^{12}$ Emilio Murillo, quien participó activamente en 1909 en actividades políticas entre los trabajadores, estuvo un año más tarde en Estados Unidos, aunque al parecer en actividades relacionadas con la música. ${ }^{13}$ El ingeniero liberal Diódoro Sánchez, miembro de diversas asociaciones gremiales, hizo un extenso viaje

\footnotetext{
${ }^{10}$ Sobre esta celebración del día del trabajo y sobre la importancia que en los medios políticos populares siguieron teniendo las referencias a la Revolución Francesa, véase Renán Vega, Gente muy rebelde, t. 4, (Bogotá: Ediciones Pensamiento Crítico, 2002),31-77.

${ }^{11}$ En el transcurso del siglo XIX, escribe Frédéric Martínez, el viaje a Europa había dejado de ser "una aventura excepcional para convertirse en una etapa codificada, 'banalizada' de la formación de las élites”. Entre 1845 y 1900 quinientos ochenta colombianos habían viajado a Europa. Frédéric Martínez, El nacionalismo cosmopolita, (Bogotá: Banco de la República, 2001), 199-203.

12 "Vicente Olarte Camacho", La Libertad, No.48, mayo 3 de 1913, Bogotá, 1. 13 "Viajero ilustre", Chantecler, No. 8, octubre 9 de 1910, Bogotá, 4.
} 
por diversos países entre 1908 y $1911 .^{14}$ José Marcelino Castro igualmente viajó a Europa por estos años. ${ }^{15}$ Además de los anteriores activistas políticos bogotanos, y del bumangués Carlos Julio Carreño, ${ }^{16}$ probablemente ningún otro activista vinculado al mundo laboral conoció Europa o Estados Unidos en la década de $1910 .{ }^{17}$

De la misma forma, fueron escasos los viajeros o inmigrantes que introdujeran al país referencias a corrientes políticas radicales durante aquella década. En 1910 un extranjero llamado Julián J. Cubellos dictó al parecer una conferencia de carácter "anarquista" en Barranquilla, por lo que fue encarcelado y luego expulsado del país. Cubellos dictaría otra charla de tenor similar en la misma ciudad en febrero de $1915 .{ }^{18}$ El español Pedro González Blanco, por su parte, dictó conferencias en Bogotá y Zipaquirá en 1911, y aunque se limitó a defender la doctrina liberal y a instar a los obreros a organizarse, fue agredido por un grupo de conservadores. ${ }^{19}$ También

14 "Un colombiano en Europa", El Proteccionista, No. 30, junio 10 de 1911, Bogotá, 1; "Dr. Diódoro Sánchez", La Libertad, No. 36, septiembre 10 de 1912, Bogotá, 2.

15 Justo Ladrón de Guevara, “José Marcelino Castro”, La Libertad, No. 48, mayo 3 de 1913, Bogotá, 1-2.

${ }^{16}$ Julio César Acelas, "Obreros y artesanos de Bucaramanga: organización, protagonismo e ideología, 1908-1935” (monografía historia Universidad Industrial de Santander, Bucaramanga, 1993), 252.

17 Pepe Olózaga, Tomás Uribe Márquez, Francisco de Heredia y Biófilo Panclasta viajaron al exterior durante la década de 1910 pero en ese momento no tenían ningún contacto con organizaciones populares, siendo conocido solamente Panclasta. En los años veinte serán importantes activistas del socialismo.

18 "Conferencia anarquista", República, febrero 3 de 1915, Barranquilla, 2.

19 "La conferencia de González Blanco", La Capital, No. 39, marzo 31 de 1911, Bogotá, 2; "Cultura extrauniversitaria”, El Proteccionista, No.22, abril 9 de 1911, Bogotá, 3; "Conferencia en Zipaquirá”, El Proteccionista, No. 26, mayo 12 de 1911, 2; "Ataque a González Blanco", El Liberal, mayo 4 de 1911, Bogotá. 
visitó el país como conferencista el argentino Manuel Ugarte en 1912. ${ }^{20}$

De esa exigüidad de los contactos personales de los activistas colombianos con el exterior se podría sacar la conclusión de que las doctrinas radicales en este país carecieron de universalismo, o incluso que por su provincianismo sus ambiciones de cambio fueron muy pobres. Hasta las referencias de la prensa socialista y obrerista a los publicistas europeos del socialismo podrían afianzar esa idea, puesto que allí se les concedió un lugar modesto. Entre esos activistas se tenía algún conocimiento de los más sobresalientes autores socialistas, tal vez debido a referencias de la prensa o a textos de vulgarización. El periódico La Libertad, por ejemplo, publicó pequeños textos de Jean Jaurès, Karl Liebknecht y Augustin Hamon, y mencionó en algunas ediciones a otros intelectuales socialistas o anarquistas europeos. ${ }^{21}$ En ocasiones una publicación insertó fragmentos de periódicos europeos o hizo referencia a sucesos o personajes que simbolizaban opciones políticas radicales, como Ravachol o Ferrer ${ }^{22}$ Con todo, aquellas referencias denotaban un conocimiento borroso de las doctrinas socialistas. En este punto podemos preguntarnos si la imprecisión de sus conocimientos doctrinarios nacía de algún factor que pudiera considerarse un hándicap político, y sobre todo, si ella misma constituía un hándicap.

\footnotetext{
20 "Manuel Ugarte", El Tiempo, noviembre 26 de 1912, Bogotá, 3.

21 "Páginas socialistas", La Libertad, No. 53, 56, 69, junio 14, julio 11, diciembre 12 de 1913, Bogotá; “Qué es socialismo?", La Libertad, No.116, marzo 17 de 1916, 2.

${ }^{22}$ Juan Francisco Moncaleano reclamó de manera vehemente seguir la senda del anarquista español Francisco Ferrer, quien a fines de 1909, según un alarmado periodista conservador, era admirado por algunos republicanos y liberals, "Los defensores del anarquismo", Los Principios, noviembre 7 de 1909, Bogotá, 1.
} 
En sentido inverso, si aquellos activistas debieron haber poseído un refinado conocimiento de las doctrinas socialistas. Y se podría responder que, considerada desde su propia perspectiva, aquella situación no constituía un déficit, estando determinada no por sus dificultades para acceder a textos doctrinarios sino más bien por su desdén a adherir a un universo homogéneo doctrinariamente. La intervención de los activistas obreristas en la arena política no estuvo sustentada en la vindicación de un socialismo que requiriera exhibirse ligado a un canon universal. Su socialismo, aunque podía diferir del patriotismo tradicional, remitía a una patria que no requería imperiosamente la destrucción de la idea nacional.

En la experiencia política de aquellos activistas obreristas y socialistas, efectivamente, la noción de patria ocupó un lugar central. Veneraron a los héroes de la Revolución Neogranadina porque sus acciones grandiosas remitían no sólo al nacimiento de la nación colombiana sino también a un momento en que aún no habían surgido las nocivas divisiones partidistas ni los intereses particulares, egoístas, entre los líderes de la república. Así, representaron a los héroes de la independencia como hombres cuyoúnicointerés había sido el bien y la grandeza de la patria. ${ }^{23}$ Para esos activistas, la Revolución Neogranadina era el origen y el destino de la nación colombiana: el objeto de la intervención en la arena política era culminar el proyecto de independencia nacional frente a las demás naciones, pero también era

${ }^{23}$ Ver, entre otros, los siguientes artículos: Ignacio J. Correal, "Unámonos", La Razón del Obrero, No. 1, marzo 12 de 1910, Bogotá, 1; "El Centenario de nuestra Independencia”, La Integridad Nacional, No. 17, marzo 20 de 1910, Bogotá, 2; Rafael Gutiérrez, "11 de noviembre", La Libertad, No. 28, noviembre 11 de 1911, Bogotá; “SSarcasmo?”, El Obrero Colombiano, No. 20, junio 30 de 1917, Bogotá, 1-2. 
culminar el proyecto de libertad, igualdad y fraternidad que debía cobijar a todos los ciudadanos. Moncaleano llamó a propósito a "completar la obra de Bolívar". Y otro publicista aludió a Antonio Nariño como un "verdadero apóstol de la democracia, pues no solo la predicó, sino que la practicó, y por eso donde hubo despotismo implantó la igualdad y convirtió en República de todos lo que fue odiosa Monarquía". ${ }^{24}$ Se reclamaban de una patria específica y podían extrañarse de que un ciudadano pudiera no tenerla. Así, en el periódico $E l$ Domingo alguien se definió por oposición a los católicos, los cuales, dijo, "no tienen patria, son cosmopolitas". ${ }^{25}$ Tal afirmación de pertenencia a menudo se expresó como una desaprobación rotunda de los hombres de partido, que según ellos, no tenían de la patria sino un concepto privado, interesado, egoísta, que les permitía jugar con sus angustias y lucrarse de sus recursos.

Pero al afirmar su pertenencia a la nación colombiana tendieron al mismo tiempo a concebirla como un tipo de comunidad política que podía conciliarse de manera armoniosa con otras naciones, e incluso podía desaparecer. Arquimedes Buitrago escribió en Bucaramanga que, siendo loable amar a la patria, el patriotismo ya no debía entenderse como en el pasado: "Hoy es un amor sin locura, sin egoísmo, sin arrebatos: un amor suave y tranquilo que impele al buen ciudadano a desear la prosperidad y la paz del país, para que todos los nuestros y cuantos en él habiten, disfruten

\footnotetext{
24 "Dos fechas", El Ravachol, No.4, julio 17 de 1910, Bogotá, 2; "Discurso pronunciado en el barrio obrero de Chapinero por el señor Alberto Navarro el $1^{\circ}$ de mayo", El Partido Obrero, No. 16, mayo 13 de 1916, Bogotá, 2-3; "El homenaje obrero", El Obrero Colombiano, No. 24, agosto 11 de 1917, Bogotá, 1-3.

25 "Se quiere pisotear la bandera nacional", El Domingo, julio 14 de 1912, Bogotá, 1.
} 
de garantías y holgura, que son los bienes supremos de las naciones". Al tenor de los inventos técnicos que aproximaban a los hombres de todas las latitudes, la tendencia de la humanidad era al acercamiento, pero en Buitrago ese ideal universal de fraternidad no anulaba el lugar de la patria. ${ }^{26}$ Una idea semejante expresó Marco Tulio Amorocho, uno de los más destacados activistas bogotanos, al decir que en una sociedad organizada para la rapiña, el chauvinista y el burgués podían concebir la patria como un instrumento de su egoísmo, de manera que para ellos eran perfectamente lícitas las depredaciones y los crímenes cometidos en su nombre. Frente a esa concepción, los socialistas abrazaban la causa de la paz entre las naciones, pues la patria era, "un concepto de cariño, que no excluye, pero que más bien cultiva y exalta el amor a la humanidad". Por eso el socialista amaba al extranjero, porque en él veía a un hermano que trabajaba por el bienestar del género humano. ${ }^{27}$

El socialismo de estos tiempos le imponía a los activistas que se reclamaban de él una noción amplia de patria, como aquella "porción de una misma familia que tiene a su cargo el cuidado de un lote de la Heredad común". Por eso se sentían compelidos a honrar a aquellos que en los distintos países se esforzaban por desarrollar valores como la libertad y la civilización, que permitían a la humanidad alcanzar su destino. ${ }^{28} \mathrm{O}$ valores como el servicio al pueblo, pues como lo afirmó un periódico de Tolú: "Quien sirve al pueblo sirve a la

${ }^{26}$ Arquimedes Buitrago, "20 de Julio", El Obrero Moderno, No. 16, julio 19 de 1913, Bucaramanga, 2.

${ }^{27}$ Marco Tulio Amorocho, "El Partido Socialista", La Libertad, No. 136, diciembre 20 de 1916, Bogotá, 1, 2.

${ }^{28}$ Arquímedes Buitrago, "El día de la patria”, La Unión Obrera, No. 18, julio 22 de 1911, Bucaramanga, 1. 
patria; quien sirve a la patria sirve a la humanidad". ${ }^{29}$ Tal concepción permitía que esa patria de los activistas obreristas y socialistas pudiera incluso ser vista como una necesidad pasajera. En el futuro, "cuando el progreso social haga del planeta un sólo país el patriotismo no tendrá razón de ser", escribieron en El Obrero Moderno de Bucaramanga. ${ }^{30}$

Al pensar de esa manera aquellos activistas coincidían en muchos puntos con la idea de Jean Jaurès sobre la nación y sobre el rol que ella debería tener dentro del socialismo, y eso a pesar de que su obra tal vez no la conocían, o la conocían someramente. El famoso líder socialista francés había escrito que en la etapa de la humanidad en que se encontraban, la acción política de los proletarios tendría que desarrollarse de manera creciente en un marco internacional pero que durante mucho tiempo la nación aún sería la que suministraría "el cuadro histórico del socialismo, el molde de unidad donde ha de formarse la justicia nueva". Precisaba que esa afirmación no contradecía su propia reivindicación del principio de la libertad de la persona humana, pues

Sólo la nación puede libertar a todos los individuos. Sólo la nación puede suministrar a todos los medios de libre desenvolvimiento. Las asociaciones particulares, restringidas, temporales, pueden proteger por algún tiempo a grupos restringidos de individuos. Pero no hay más que una asociación general y permanente que puede asegurar el derecho de todos los individuos sin excepción, y no

29 "Por el pueblo, por la patria y por la humanidad", La Correspondencia, No. 2 , febrero 2 de 1912, Tolú, 1.

30 "El patriotismo", El Obrero Moderno, No. 20, diciembre 27 de 1913, Bucaramanga, 2. 
sólo de los individuos vivos, sino de todos los que han de nacer en la serie de las generaciones. ${ }^{31}$

Aquel patriotismo jauresiano de los socialistas colombianos dejaba en un punto de ser apacible, puesto que ellos repudiaban a las naciones que abatían la dignidad de las demás. La no interrumpida presencia imperial de Estados Unidos tendió a hacerles ver la escena internacional como un tablero donde unas naciones poderosas acechaban a las débiles: por un lado naciones depredadoras, bárbaras, con Estados Unidos a la cabeza, y por el otro, naciones amenazadas. El esquema lo sintetizó un escritor de amplia acogida, José María Vargas Vila, en uno de sus títulos más conocidos: Ante los bárbaros (los Estados Unidos y la guerra) El yanqui: he ahi el enemigo. ${ }^{32}$ En la denuncia de ese enemigo se comprometieron por entonces casi todos los políticos colombianos y con tal fin dio varias conferencias en Bogotá Manuel Ugarte a finales de 1912. En el periódico obrerista $L a$ Libertad exaltaron al argentino como defensor del proletariado y como difusor de alguna manera del socialismo, pero en él vieron ante todo a un publicista de la cohesión de los países suramericanos "contra el imperialismo yanqui"; a un intelectual cuyos discursos les permitía reafirmarse en que los yanquis eran "una raza maldita". ${ }^{33}$

Manuel Ugarte había arribado a Bogotá desde México, y ello no era casual pues a partir de su revolución desde allí se proyectó con un vigor renovado la contraposición de la raza latina, dotada de espiritualidad, con la raza anglosajona, caracterizada por su pragmatismo y su inhibición para avasallar. Pero a los activistas obreristas y socialistas no les interesó

\footnotetext{
31 Jean Jaurès, "Páginas socialistas", La Libertad, No. 56, julio 11 de 1913, Bogotá, 2.

${ }^{32}$ Un artículo donde aluden a los "bárbaros del norte": "Por la patria", $L a$ Integridad Nacional, No. 19, abril 3 de 1910, Bogotá, 1.

33 "Manuel Ugarte", "La conferencia del domingo", La Libertad, No. 40, diciembre 7 de 1912, Bogotá, 2-3.
} 
para nada la revolución como gesta militar. ${ }^{34}$ En uno de los poquísimos artículos sobre el tema, publicado en La Libertad, contrapusieron la obra de reivindicación obrerista emprendida en Colombia desde una perspectiva gradualista que utilizaba a los partidos políticos existentes, con la manera como los socialistas mexicanos adelantaban en ese momento su obra:

En la guerra de Méjico, a imitación de la Revolución francesa de 1793 han surgido los sentimientos anarquistas más bien que los socialistas. En el campo del proletariado ha germinado la idea de la destrucción del principio de autoridad, por considerarse como un peligro permanente contra los intereses del trabajador. Allí no se lucha ya por partidos políticos sino por clases sociales. Se quiere evitar el regreso de Porfirio Díaz al Poder, porque él significa la continuación de una dictadura que, para subsistir, destruyó todo elemento de equidad e implantó la hegemonía de los poderosos.

De esa manera, agregaban, los socialistas mexicanos han "prolongado la guerra, aniquilando la obra de progreso y quizá preparando el dominio de los yanquis". ${ }^{35}$

En el nuevo Partido Obrero que se intentó organizar en Bogotá en 1916 no podían faltar las referencias a problemas y sujetos más allá de las fronteras gremiales y

\footnotetext{
${ }^{34}$ Pepe Olózaga, que en la década de 1920 se vincularía a los grupos socialistas colombianos, al parecer militó en las filas zapatistas. La participación de colombianos en la Revolución Mexicana fue, sin embargo, muy escasa. Ver Ignacio Torres Giraldo, Los inconformes. Historia de la rebeldía de las masas en Colombia, t. 3, (Bogotá: Editorial Latina, 1978), 739.

35 "Meditaciones", La Libertad, No. 53, junio 14 de 1913, Bogotá, 2. Esa preocupación porque el conflicto pudiera conducir a la desintegración de la nación mexicana y a la intervención de Estados Unidos fue central en el cubrimiento de la prensa colombiana a ese conflicto. Se trataba ante todo de un conflicto militar y hubo por lo tanto poco espacio para las disputas sociales allí escenificadas, siendo por lo demás Villa y Zapata presentados simplemente como hombres sanguinarios y barbarous. Marlie Moscoso, "La revolución mexicana desde la prensa colombiana", (monografía historia, Universidad Nacional de Medellín, 1992).
} 
nacionales, sirviendo ellas para justificar la acción política de los trabajadores. "En todos los países de la tierra que forman el concierto de las naciones civilizadas, a los obreros se les ha señalado el puesto a que tienen derecho en la marcha de la civilización moderna", y a ese proceso no podía ser extraña Colombia, señalaron en el manifiesto fundacional. ${ }^{36}$ Aunque fue efímero y enarboló demandas modestas, ese partido constituyó una experiencia valiosa para muchos activistas obreristas y socialistas, que se apropiaron de nuevos elementos de acción política como la huelga — que devino un mecanismo de acción laboral legítimo- y que pasaron a considerar la organización a escala nacional como una necesidad.

\section{Entre el patriotismo y la vocación internacionalista}

La desaparición de las actividades tendientes a organizar el Partido Obrero no impidió que en diversos lugares del país algunos activistas continuaran las labores de propaganda y organización entre los trabajadores, aunque sin una estructura de carácter nacional o regional que las aunara. Esta situación cambió a principios de 1919 cuando empezaron en Bogotá los trabajos tendientes a la creación del Partido Socialista. Los miembros de $\mathrm{su}$ primer directorio juraron defender los intereses "sagrados de la Patria y del Partido", y en la plataforma con que él fue dado a conocer, lo imaginaron como "el verdadero exponente de la democracia, el redentor de las clases desvalidas y el llamado a darle timbre y

\footnotetext{
36 "Manifiesto a los obreros colombianos", El Partido Obrero, No. 1, enero 22 de 1916, Bogotá, 1. Allí mismo alegaron que, "no existen partidos honrados sino que la humanidad sólo se divide en dos clases: la una, que trabaja y sufre hambre y miseria; la otra, que consume y no produce o sea en la primera las abejas laboriosas; en la segunda, los zánganos que se mantiene con el trabajo de estas, entregados a su vida de molicie y disipación".
} 
progreso a la Patria". ${ }^{37}$ Ese rol que los socialistas se adjudicaron, de abanderados de la patria nacional, lo reclamó también el director del periódico El Piloto, Justo García, quien dijo proponerse trabajar allí "en bien de la Patria y de los sagrados intereses de la clase obrera". Los obreros, señaló, debían unirse para vencer a unos "señores despiadados" que habían olvidado que "somos hijos de una misma Patria, e independizados del yugo español por unos mismos héroes, los que tiñeron con el derramamiento de sangre generosa y patricia el santo suelo de la Gran Colombia, para darnos a perpetuidad y sin distinción de cunas ni matices políticos, el sagrado bautismo de hombres libres". 38

En los inicios del Partido Socialista buena parte de sus agenciadores siguieron concibiendo el socialismo como la culminación del proyecto de los fundadores de la nación colombiana, confiscado, según ellos, por una "ignominiosa oligarquía", o por "los ricos". Un escritor resumió ese horizonte diciendo que "los próceres no hicieron sino sembrar la semilla de la Libertad en Colombia, y el socialismo debe hacerla germinar y dar sus frutos". ${ }^{39}$ En los periódicos que declararon su adhesión al partido se siguieron publicando por lo tanto artículos laudatorios de los próceres de la Revolución Neogranadina, cuyo heroísmo y generosidad se continuó contraponiendo

\footnotetext{
37 "La fiesta del trabajo", Gaceta Republicana, mayo 2 de 1919, Bogotá, 1; "La plataforma socialista”, La Libertad, No. 192, mayo 28 de 1919, Bogotá, 3. En idéntico sentido se pronunciaron en "Manifiesto del Directorio Socialista de Bogotá”, La Libertad, No. 227, noviembre 14 de 1920, 2.

38 Justo García, "Nuestros propósitos. El Piloto y los principios socialistas", El Piloto, No. 1, febrero 25 de 1919, Bogotá, 1.

39 "La primera Convención socialista de Colombia", La Libertad, No. 198, agosto 14 de 1919, Bogotá, 2; Juan de Dios Romero, "La patria de los ricos", La Libertad, No. 201, octubre 20 de 1919, Bogotá, 2. En el mismo sentido Santiago Martínez G., "Las huelgas", La Libertad, No. 206, febrero 14 de 1920, Bogotá, 3.
} 
al egoísmo de los políticos. ${ }^{40}$ Esa vindicación de la nación colombiana como el marco en que debía seguirse desarrollando la acción transformadora del proletariado encontraba correspondencia con un tipo de socialismo que en Europa y Estados Unidos diversos publicistas defendían y al cual la prensa socialista colombiana dio cabida. Así, en el periódico El Luchador de Medellín publicaron pequeños textos de Jean Jaurès, Max Nordau, Theobald Ziegler, León Tolstoi y Orison Swett Marden. ${ }^{41}$ En El Baluarte de Girardot reprodujeron una apología del líder sindicalista de Estados Unidos Samuel Gompers. ${ }^{42}$ En La Libertad de Bogotá elogiaron al socialista español Pablo Iglesias. ${ }^{43}$

Ese socialismo que llamaba a construir un orden social más justo, aunque no al precio de una supresión absoluta de las diferencias y de la libertad, se contraponía al comunismo, que remitía directamente al bolchevismo. El fin que persigue el Partido Socialista, dijo un activista de Medellín, es "mejorar la suerte del proletariado", lo cual nada tiene que ver con "la rebeldía febril y apasionada de un estulto comunismo que porta como enseña democrática las armas mil veces repudiadas de la guerra. No; nuestro derrotero es tan amplio que permite divisar desde cualquier punto de su órbita horizontes

\footnotetext{
${ }^{40}$ Arístides Zapata, "Bolívar", El Luchador, No. 70, julio 19 de 1919, Medellín, 1; "Centenario de Boyacá”, El Baluarte, No. 41, julio 24 de 1919, Girardot, 3.

41 "Grandes ideas", El Luchador, No. 81, 87, 88, 100, septiembre 2, 23, 26, noviembre 8 de 1919, Medellín, 1. En la misma sección incluyeron los textos de León Tolstoi y Orison Swett Marden. En otro número evocaron a Danton para llamar a los obreros a la acción política en reclamo de sus derechos: “'Atrevámonos”, El Luchador, No. 68, julio 11 de 1919, 1.

42 Jorge Trideman, "Los hombres del socialismo actual", El Baluarte, No. 26, abril 3 de 1919, Girardot, 2.

43 "Don Pablo Iglesias", La Libertad, No.196, julio 4 de 1919, Bogotá, 2.
} 
más pletóricos de civilización”. ${ }^{44}$ En Medellín, así como en Bucaramanga, entre quienes adhirieron al Partido Socialista parece haber predominado entonces el repudio de "un socialismo insano, una especie de comunismo, que va contra los ricos, que no respeta castas, clases ni condiciones", como querían hacerlo ver los malquerientes del partido al asociarlo al bolchevismo. ${ }^{45}$ En esto fueron enfáticos también los líderes del Sindicato Central Obrero de Bogotá, iniciador del Partido Socialista, cuando afirmaron que los métodos de reivindicación obrera practicados en los "países civilizados", iban "contra el comunismo y el anarquismo", por ser estos unos principios que requerían una mayor perfección humana. De esta manera, la denominación que el gobierno daba al movimiento obrero como "anarquista o bolcheviquista" no era más que una forma de bloquear sus justas reivindicaciones. ${ }^{46}$

Tal socialismo moderado, como algún activista local lo designó, dejó un lugar, aunque condicionado, a la defensa de la patria nacional. En la primera plataforma socialista consignaron que en caso de una agresión "triunfante" e injusta de otro país contra Colombia, los socialistas primero debían interponer su influencia como mediadores, pero si esto fallaba deberían "acudir en

44 “Comunismo no... no...”, El Luchador, No. 77, agosto 17 de 1919, Medellín, 2 .

45 "No aceptamos componendas", El Luchador, No. 85, septiembre 16 de 1919, Medellín, 1; "El socialismo y el comunismo", La Unión Obrera, No. 1, septiembre 20 de 1919, Bucaramanga; "Terrorismo? Bolshevikismo?", El Yunque, No. 75, febrero 25 de 1919, Facatativá, 1.

${ }^{46}$ Se reclamaron seguidores de un "socialismo científico" preconizado entre otros por "Bedel, Jaurès, Fernando Naudier, Hamón, Chirac, Faguet, Pablo Iglesias, Janet, Louis Bertrand, Bakounine, C. Marx, Enrique Malatesta, Laveleye, Lacy, W. Holmes, Blackie, Sydney, Weebb, etc.”. Véase "Manifiesto del Sindicato Central Obrero a los artesanos de la República", La Libertad, No.187, abril 3 de 1919, Bogotá, 1-2. 
defensa de su Patria, siempre que estén completamente seguros de la justicia de su causa y que van a luchar por el bienestar social de todos sus hermanos". ${ }^{47}$ En el socialismo bolchevizado que comenzó tenuemente a emerger por estos mismos años, la perspectiva fue distinta. Manifestaron su negativa rotunda a participar no sólo en guerras civiles sino en guerras internacionales, considerando que la nación colombiana tenía sentido únicamente en la medida que permitiera el avance hacia su propia eliminación como nación particular. El directorio socialista del Cauca escribió a propósito que, "las palabras patria y partido tienen hoy para los pueblos escarmentados, muy otro significado del que tuvieron ayer: nuestra patria es el mundo, nuestro partido la humanidad que padece". ${ }^{48}$

En Popayán fue justamente donde la Revolución Rusa fue elogiada más pronto y más intensamente, como aurora de la humanidad oprimida. ${ }^{49}$ Ese acontecimiento, que devendría tan importante en la experiencia socialista, no había concitado entre los activistas volcados al mundo popular, sin embargo, una euforia de que se tenga noticia entre los años 1917-1918. El suceso había sido lejano no solamente para ellos sino para los políticos de las demás corrientes, que encontraban en la prensa nacional poco espacio para la política

47 "La plataforma socialista", La Libertad, No. 192, mayo 28 de 1919, Bogotá, $2-3$.

48 "Manifiesto del Directorio Socialista Departamental a los obreros del Cauca”, La Ola Roja, No. 8, abril 23 de 1920, Popayán, 1-2.

49 Fueron muy pocos los artículos consagrados específicamente a la Revolución Rusa en los periódicos obreristas y socialistas durante el periodo 1917-24. Entre ellos: Enrique Santos, "Lenine", La Libertad, No. 203, noviembre 30 de 1919, Bogotá, 1; sin título, La Ola Roja, No. 3, marzo 19 de 1920, Popayán, 1-2; N. Tasin, "Lenine", La Ola Roja, No. 7, abril 16 de 1920, 4; "Lenine juzgado por Gorki", La Libertad, No. 228, noviembre 30 de $1920,3$. 
internacional en general. Durante sus primeros meses de existencia, la revolución bolchevique debió parecerle a los activistas políticos obreristas y socialistas una revolución más, esto es, otro cambio de gobierno que utilizando las estructuras estatales existentes colocaba en el poder a nuevos personajes. La información que la prensa ofrecía, generalmente a partir de los cables de los Aliados, así lo hacía deducir. Bien es cierto que el poder derrocado era presentado como una monarquía reaccionaria pero las intenciones de los revolucionarios rusos eran comprimidas en los adjetivos "maximalismo", "extremismo", "anarquismo". ${ }^{50}$

A medida que tuvieron un conocimiento menos impreciso de las actividades y los pensamientos de los bolcheviques, entre los intermediarios políticos volcados al mundo popular creció la simpatía por la revolución de octubre. A mediados de 1919 varias calles de un barrio de Bogotá fueron bautizadas con el nombre de sus dos más prominentes jefes, Lenin y Trotsky. En octubre de ese año Carlos Melguizo, uno de los principales líderes del Partido Socialista, escribió una serie de artículos en los que, defendiendo el sentido y la viabilidad de su organización, la ligó con los líderes bolcheviques, especialmente con Lenin, a quien "los socialistas, o por lo menos la mayor parte de nosotros, reconocemos (...) como nuestro jefe, y predicamos como base de nuestra asociación esta sola frase: 'amaos los unos a los otros", 51 dijo. Y a finales de este mismo año, cuando en la prensa se dijo que Lenin había sido asesinado, en El Luchador alguien escribió que aquel había sido "un águila caudal,

\footnotetext{
${ }^{50}$ Ver, por ejemplo, "Un bolsheviki en viaje para Bogotá", El Tiempo, febrero 22 de 1919, Bogotá, 2.

51 "Visitando Chapinero", El Tiempo, julio 5 de 1919, Bogotá, 5; "Lo que es el socialismo en Colombia", El Tiempo, octubre 13 de 1919, 3.
} 
un gran apóstol y un formidable luchador que tuvo el valor de encargarse del Gobierno de Rusia en pleno caos (...) Tengo para mi que la gran figura de Lenine, con el tiempo, adquirirá proporciones gigantescas, por su valor, por su ciencia, por su energía y quizás por su sacrificio". ${ }^{52}$

Por esta época, empero, no todos los activistas obreristas o socialistas fueron poseídos por aquel entusiasmo hacia la Revolución Rusa. Jacinto Albarracín vio el bolchevismo como una reacción extremista al "despotismo imbécil" que era el zarismo. Ante ese sistema retardatario que iba contra la nación porque pretendía gobernarla contra su voluntad, lo de los bolcheviques, "a falta de otros remedios parece que es como quemar las basuras para desinfectar la casa", queriendo con ello al parecer significar que se trataba de una solución transitoria que fallaba en restituir el equilibrio necesario al orden social. ${ }^{53} \mathrm{Y}$ otro activista afirmó que confundir el socialismo colombiano con el "bolshevikismo ruso" o el comunismo o el anarquismo, sólo podía ser obra de la actitud maliciosa de "los enemigos sempiternos de las clases trabajadoras para mantener firme el imperio del AMO que nos veja y nos explota". El socialismo democrático que vindicaba, lo concebía él como el "único verdadero baluarte de la Patria mutilada, ultrajada y llorosa, puesto que en él no caben necios prejuicios ni rastreras ambiciones partidaristas". ${ }^{54}$

52 "Manjarrés y Lenin", El Luchador, No. 100, noviembre 8 de 1919, Medellín, 2. El autor del artículo firma con el seudónimo de Miguel Strogoff.

53 Jacinto Albarracín, "El socialismo en Colombia”, El Piloto, No. 1, febrero 25 de 1919, Bogotá, 2; Jacinto Albarracín C., "De qué se trata", La Libertad, No. 197, julio 22 de 1919, Bogotá, 2.

54 "Salus populi", El Luchador, No. 99, noviembre 5 de 1919, Medellín, 1; "Varios esfuerzos", El Luchador, No. 100, noviembre 8 de 1919, 1. El autor de estos dos artículos se asignó el seudónimo de Juan Lanas. 
La Revolución Rusa, pues, no generó consenso en un primer momento entre los activistas inmersos en el mundo popular, y pronto esa discrepancia irá a hacerse un motivo de fractura. En lo que al parecer sí hubo un considerable acuerdo en los primeros meses de existencia del Partido Socialista fue en la necesidad de ligar sus actividades a las corrientes socialistas internacionales. Esa inquietud se manifestó incluso antes de su fundación, en mayo de 1919, como se vio en una reunión preparatoria donde encargaron a varios estudiantes de "establecer y estrechar relaciones con los principales sindicatos obreros del Exterior; y de mantener al Partido al corriente del movimiento mundial sobre legislación obrera". ${ }^{55}$ Los frutos de esa tarea no se conocen, pero el Sindicato Central Obrero de Bogotá había recibido de la Confederación Panamericana del Trabajo — con sede en Washington y liderada por la American Federation of Labor - una invitación al Tercer Congreso Obrero Panamericano, a realizarse en Ciudad de México a partir del 12 de julio de 1920, siendo transferida esa invitación al Directorio Socialista. Y pese a que un grupo planteó la inconveniencia de que obreros colombianos participaran en un evento liderado por una organización estadounidense, un representante colombiano asistió al Congreso, que debió realizarse finalmente en Texas. De acuerdo a Ignacio Torres Giraldo este fue "el primer vínculo internacional del proletariado colombiano". ${ }^{56}$

El interés por tejer tal tipo de vínculos debía por entonces haber adquirido alguna importancia pues en febrero de 1920 los socialistas habían hecho pública

\footnotetext{
55 "El Partido Obrero", El Tiempo, diciembre 10 de 1918, Bogotá, 2.

56 "Congreso obrero panamericano", La Lucha, No. 17, julio 11 de 1920, Girardot, 1; "Congreso obrero panamericano", La Lucha, No. 29, octubre 3 de 1920, 1; Ignacio Torres Giraldo, Los inconformes, ... 702-704, 707 y 718-720.
} 
una resolución invitando a todos los centros socialistas y obreros suramericanos a formar la Confederación del Trabajo, la cual tendría por objeto "velar por los obreros del Continente, sin distinción de nacionalidades", para cuya materialización se procedería a reunir un "Congreso Internacional Socialista". ${ }^{57}$ La ambiciosa propuesta no se concretó, y las relaciones internacionales de los socialistas colombianos continuaron siendo muy escasas. En los periódicos socialistas se incluían por entonces algunas alusiones positivas a la experiencia bolchevique, y sobre todo a sus líderes, pero la Revolución Rusa no representó durante varios años más que un vaga referencia percibida a través de los escritos de sus jefes y propagandistas, y un ejemplo dudoso, divisado a través de las imprecisas informaciones de la prensa. Pese a ello, el gobierno comenzó a inquietarse por la presencia de supuestos bolcheviques.

La insólita agitación social de los años 1918-1920 — las huelgas prácticamente se iniciaron en el país- debió ser para los conservadores un hecho de auténtica gravedad, dadas las crecientes simpatías por la Revolución Rusa entre los activistas políticos ligados al mundo laboral. Jesús María Yepes, un influyente conservador, expresó en 1919 esa inquietud diciendo que en esos momentos, "cuando la humanidad se transforma y renueva, una tendencia niveladora y anarquizante ha aparecido de súbito en el escenario de la política nacional: el socialismo, la hez de la civilización contemporánea, [que] ha venido como elemento perturbador de nuestras luchas sociales". ${ }^{58}$ El gobierno, por lo tanto, alertó a sus agentes

\footnotetext{
${ }^{57}$ Directorio Ejecutivo Nacional Socialista, "Resolución No 12", La Libertad, No. 208, marzo 20 de 1920, Bogotá, 2.

58 "El socialismo y sus doctrinas", citado por Gerardo Molina, Las ideas socialistas en Colombia, $2^{a}$ ed., (Bogotá: Tercer Mundo Editores, 1987),230.
} 
diplomáticos y a las autoridades portuarias nacionales para impedir la llegada de "extranjeros perniciosos". ${ }^{59}$ Pero el espectro del comunismo podía simultáneamente servir de explicación para asuntos sociales embarazosos, y así en marzo de 1919 el gobierno invocó la "existencia del anarquismo y del bolcheviquismo" para justificar la represión contra una manifestación de artesanos. Líderes de estos respondieron negando cualquier vinculación con esas doctrinas y alegaron que esa imputación era sólo una forma de "desvirtuar la organización obrera."

En realidad los extranjeros simpatizantes con el socialismo que llegaron a Colombia durante el periodo de más dinamismo del Partido Socialista (1919-1921) fueron muy pocos y su acción bastante restringida. El más importante de ellos fue el italiano Vicente Adamo, que en el lejano departamento de Córdoba desarrolló actividades de organización entre los trabajadores y especialmente entre colonos ansiosos por hacerse a un trozo de tierra para cultivar. Adamo así mismo creó una rama del PS en Montería. ${ }^{61}$ El peruano Nicolás Gutarra, de afinidades anarquistas, que había llegado al país a comienzos de la década de 1920, por su parte, lideró las luchas de los inquilinos de Barranquilla a finales de 1923, pero al parecer no se integró con los socialistas de

\footnotetext{
${ }^{59}$ Diversos documentos oficiales dan cuenta de esa inquietud del gobierno. En septiembre de 1919 el Ministerio de Relaciones Exteriores dio "instrucciones a los Agentes diplomáticos y consulares de la República en el Exterior a fin de que no expidan pasaportes sino a las personas que comprueben suficientemente su honorabilidad y buena conducta”. Ver: Archivo General de la Nación (A.G.N), República, Fondo Ministerio de Gobierno, sección $4^{a}$, t. 129 , f. 462 .

60 "Manifiesto del Sindicato Central Obrero a los artesanos de la república", La Libertad, No. 187, abril 3 de 1919, Bogotá, 1, 2.

${ }^{61}$ Orlando Fals Borda, Historia doble de la Costa, t. 4, (Bogotá: Carlos Valencia Editores, 1986), 140A-161A; "Solidaridad", Gaceta Republicana, mayo 3 de 1919, Bogotá, 1.
} 
otras partes del país. ${ }^{62}$ Los grupos ligados al socialismo colombiano tampoco desarrollaron muchas actividades que denotaran su involucramiento con asuntos internacionales. En 1921 una hoja anónima amenazó al Embajador de Estados Unidos en Colombia en protesta por el juicio que se le seguía allí a los anarquistas Sacco y Vanzetti. ${ }^{63} \mathrm{Y}$ en enero de 1923 fue convocada en Bogotá una reunión para protestar contra Francia por haber invadido territorio alemán como presión para que este país cumpliera los dictados del Tratado de Versalles, que los socialistas colombianos criticaron por no representar sino "la soberbia del vencedor y el acatamiento forzoso del vencido". ${ }^{64}$

Los líderes del Partido Socialista ni siquiera dieron pasos concretos para establecer relaciones con las corrientes socialistas internacionales luego de que el Tercer Congreso Socialista, realizado en noviembre de 1921, expresara una mayor preocupación por la situación internacional y por los asuntos doctrinarios. Allí se planteó el novedoso objetivo estratégico de constituir una sociedad sin "explotadores ni explotados" en la que fueran abolidas las clases sociales, aunque dentro de un proyecto a largo plazo que en lo inmediato contemplaba un conjunto de reformas tendientes a obtener más libertad y bienestar social. Esa radicalización del discurso tenía lugar, sin embargo, en un momento de escasa movilización popular y de crisis terminal del Partido Socialista, que dejó prácticamente de existir luego de las

62 "Expediente relacionado con la expulsión del país del extranjero Nicolás Gutarra", A.G.N., República, Fondo Ministerio de Gobierno, sección 4a, t. 185, f. 327.

${ }^{63}$ A.G.N., República, Fondo Ministerio de Gobierno, sección 1ª t. 843, f. 489. ${ }_{64}$ "En una reunión verificada ayer en la Casa del Pueblo, un numeroso grupo de obreros protestó contra la actitud bélica de Francia", El Diario Nacional, enero 22 de 1923, Bogotá, 1. 
elecciones presidenciales de comienzos de 1922 en las que los socialistas fueron atraídos irresistiblemente en apoyo del popular candidato liberal Benjamín Herrera.

En aquel congreso de noviembre de 1921 fue propuesta, además, la adhesión del Partido Socialista a la Tercera Internacional o Internacional Comunista (IC). La iniciativa fue negada tras ser tomada en cuenta, pero su sola presentación revelaba que la revolución bolchevique había ido ganando adeptos, y sobre todo, que se había producido un cambio considerable de los puntos de referencia doctrinarios de los socialistas. ${ }^{65}$ A estos se había sumado recientemente un grupo de intelectuales - algunos de los cuales habían viajado al exterior, como Francisco de Heredia y Luis Enrique Osorio- entre quienes se escucharon justamente los mayores elogios a la Tercera Internacional. ${ }^{6}$ Sólo que dicha simpatía hacia la organización internacional de los comunistas fue recusada por algunos activistas políticos ligados a organizaciones mutuales y sindicales, quienes, llamándose "sindicalistas", fustigaron a comienzos de 1922 a los "comunistas" simpatizantes de aquella organización, la cual desestimaban por considerarla promotora de valores incompatibles con la sociedad colombiana y con las aspiraciones populares. A cambio de esa adhesión a la IC, los socialistas sindicalistas abogaron por vincularse a

\footnotetext{
${ }^{65}$ Sobre el Tercer Congreso Socialista, véase El Espectador, noviembre 13, 15, 16 y 17 de 1921, Bogotá.

${ }^{66}$ De Heredia, que provenía de una familia adinerada, había estudiado ciencias políticas en Londres, donde al parecer había conocido y adoptado las ideas socialistas. Osorio, dramaturgo, había vivido algún tiempo en Argentina. Ver María Tila Uribe, Los años escondidos. Sueños y rebeldías en la década del veinte, (Bogotá: Cestra / Cerec, 1994),75-77; "Cosas del día. Luis Enrique Osorio”, El Tiempo, diciembre 26 de 1922, Bogotá, 3.
} 
la Internacional de Ámsterdam, organización moderada de tendencia tradeunionista. ${ }^{67}$

La polémica sobre la vinculación a una $\mathrm{u}$ otra Internacional parece no haber interesado a muchos activistas, o de eso al menos no hubo registro en los periódicos. A ello contribuyó la rápida disolución del PS luego de su Tercer Congreso, quedando así el asunto de los vínculos con una organización socialista internacional reducido si acaso a preocupaciones individuales de los activistas que persistieron en sus actividades políticas. La polémica indicaba, no obstante, que el impulso tendiente a vincular las organizaciones gremiales de los trabajadores así como las organizaciones socialistas con las corrientes socialistas mundiales, era perceptible tanto entre los líderes simpatizantes con la IC como entre aquellos que eran proclives a procesos de organización más gremiales y de carácter político moderado. El grupo sindicalista había señalado que su socialismo no era internacionalista "todavía", porque apenas se estaba organizando localmente, pero que ambicionaban la "solidaridad internacional del proletariado" para sus aspiraciones de engrandecimiento económico y espiritual. En lugar de la adhesión incondicional a Moscú, se reclamaban inspirados en la Internacional de Ámsterdam, aunque "para adoptar en Colombia aquello que sea practicable dentro del medio mismo en que vivimos". Se reafirmaban además como "patriotas irreductibles en cuanto a la defensa de nuestro territorio e integridad de nuestra soberanía". ${ }^{68}$

\footnotetext{
${ }^{67}$ La carta, de enero de 1922, donde se plantea esta polémica se encuentra copiada en Julio Cuadros Caldas, Comunismo criollo y liberalismo autóctono, $3^{\mathrm{a}}$ ed., t. 2, (Bucaramanga: Editorial de Marco A. Gómez, 1938), 64-72.

${ }^{68}$ Carta copiada en Julio Cuadros Caldas, Comunismo criollo,... 70.
} 
El igualmente pequeño sector de socialistas que simpatizaban con los bolcheviques se sentía atraído no sólo por la doctrina de estos sino también por sus métodos y por la organización que habían creado para llevar a cabo la revolución en el mundo. Los líderes soviéticos consideraban que la revolución debía ser un suceso internacional que como evento liberador debía comprometer a todos los proletarios del mundo. Con ese objetivo habían creado en marzo de 1919 la Internacional Comunista, que según su propio lenguaje se proponía "luchar por todos los medios posibles, incluso la lucha armada, por el derrocamiento de la burguesía internacional y por la creación de una república internacional soviética como una etapa de transición hacia la abolición completa del Estado". La Internacional Comunista consideraba "la dictadura del proletariado como el único camino posible para liberar la humanidad de los horrores del capitalismo", y "el Poder Soviético como la forma históricamente dada de esta dictadura del proletariado". ${ }^{69}$ Ese "poder soviético" consagrado con beneplácito por los socialistas de dentro y fuera de Rusia como el único modelo legítimo de quienes aspiraban a tomar el poder en nombre de los trabajadores y la historia, daba automáticamente a los máximos líderes rusos la administración de la doctrina, los valores y los métodos de toda la organización comunista mundial. ${ }^{70}$ Siendo una revolución anticapitalista la que avizoraban los dirigentes bolcheviques, se presumía que ella estaría centrada en el mundo industrial y que los obreros serían el grupo social que la debía conducir. Incluso después

\footnotetext{
69 Second World Congress, Minutes of the Proceedings, vol. II, 145, citado en Manuel Caballero, La Internacional Comunista y la revolución latinoamericana, $2^{\mathrm{a}}$ ed., (Caracas: Editorial Nueva Sociedad, 1978), 32.

${ }^{70}$ A diferencia de las dos primeras Internacionales, que fueron una federación de organizaciones, Lenin quiso que la III fuera un auténtico partido, guiado por unos solos principios, procedimientos y dirigentes. Manuel Caballero, La Internacional Comunista y la revolución latinoamericana, ... 31-37.
} 
de adaptar esa concepción para convertir a las élites soviéticas en depositarias de la "ideología obrera" que debía guiar la revolución, ese evento fundacional de una nueva humanidad sólo podía producirse donde la clase obrera fuera numéricamente considerable y políticamente cohesionada. Ello sólo podía ocurrir en los países donde la industria estuviera desarrollada. América Latina, por lo tanto, ocupaba un lugar secundario en la escala de regiones susceptibles de pasar al socialismo, lo cual se reflejaba en la exigua atención teórica y en los pocos esfuerzos empeñados allí por la organización comunista internacional. ${ }^{71}$

En mayo de 1924, cuando los dispersos núcleos socialistas intentaron su reorganización durante el Congreso Socialista realizado en Bogotá, un pequeño grupo de jóvenes intelectuales simpatizantes de la Revolución Rusa logró controlar el evento. Enseguida hicieron aprobar entre los escasos participantes una declaración en la que rompían cualquier vínculo con los tres congresos socialistas anteriores, dieron al evento el nombre de "Primer Congreso Comunista de Colombia" y se adhirieron a la Tercera Internacional, adoptando los 21 puntos que ella exigía para admitir un partido. ${ }^{72}$ Frente a esas decisiones, Francisco de Heredia, el líder más sobresaliente de la antigua corriente socialista y crítico por eso del grupo comunista, consideró que desde Colombia no era preciso aceptar a priori todos los puntos preconizados por la Internacional de Moscú, pues el comunismo no era "un fin sino un medio", pudiéndose ellos considerar comunistas "en todo aquello que sea

\footnotetext{
71 Manuel Caballero, La Internacional Comunista y la revolución latinoamericana,.... 47-104.

72 "El Congreso Socialista se vuelve comunista", El Tiempo, mayo 6 de 1924, Bogotá, 5.
} 
practicable y aumente el bienestar de la humanidad". ${ }^{73}$ Pero poco significaba en ese momento la adhesión a la Tercera Internacional por parte de una organización que nacía muerta, como era el caso de ese esfuerzo de mayo de 1924. La discusión quedaba en el aire porque ninguno de los pequeños grupos tenía vínculos con organizaciones obreras o populares significativas, en ese momento en una aguda crisis. Los antiguos líderes vinculados a las organizaciones de trabajadores no expresaron interés en vincularse al comunismo, por lo que nuevamente el socialismo colombiano quedó convertido en una serie de líderes aislados que, dentro de movilizaciones laborales o populares de diverso tipo, continuaban predicando esa doctrina. Así, la cuestión de la inserción en las corrientes socialistas mundiales era una inquietud de escasos activistas y expresaba, más que la fortaleza de su inserción social, el ahondamiento de la distancia respecto al mundo del trabajo y sus tradiciones políticas. Los socialistas parecían no tocar ya las armonías que podían movilizar al mundo popular.

\section{El universalismo bolchevique}

Después del Congreso Socialista de 1924, el grupo comunista, cuyo más destacado líder era el periodista Luis Tejada, comenzó a realizar actividades orientadas sobre todo a difundir las ideas comunistas, sin interesarse mucho en generar dinámicas organizativas. El grupo dedicó especial atención al estudio de textos de vulgarización marxista y a los discursos de los líderes bolcheviques, entonces disponibles en una modesta cantidad en el país, actividad en la que participó un

${ }^{73}$ Francisco de Heredia, Programa del Partido Socialista (Bogotá: Editorial Santafé, 1925), 36. 
oscuro emigrado ruso, Silvestre Savitsky. ${ }^{74}$ Pero si el grupo comunista de Tejada no tuvo una influencia importante en las actividades políticas de los trabajadores — Tejada murió en septiembre de 1924-, diversos activistas adoptaron por entonces el ideario comunista y reconocieron de manera entusiasta la autoridad de la Internacional Comunista. El más destacado de ellos quizá fue Tomás Uribe Márquez, quien escribió en 1925 que la "verdadera expresión del proletariado revolucionario mundial" radicaba en los principios establecidos por el tercer congreso de la IC de 1921, los cuales "hermanan a los humanos, por encima de las patrias, en el apostolado y en la lucha". ${ }^{75}$

Uribe participó junto a Pepe Olózaga ${ }^{76}$ y Silvestre Savitsky en la tentativa de crear un partido comunista clandestino a partir de un minúsculo grupo de activistas que preparó un programa y exhortó a los trabajadores a

\footnotetext{
${ }_{74}$ Savitsky fue expulsado del país en julio de 1925. Ver, "El 'camarada' Zawinsky será expulsado?", El Espectador, julio 10 de 1925, Bogotá, p. 1. Por la misma época fueron expulsados el alemán Rodolfo Von Wedell, de participación marginal en actividades políticas en Cali, y el griego Evangelista Priftis, acusado de actividades comunistas en Neiva pero al parecer víctima solamente del celo del gobernador por complacer los temores del gobierno nacional. Véase, Ignacio Torres Giraldo, Los Inconformes, t. 3,...740; A.G.N., República, Fondo Ministerio de Gobierno, sección 1ª , t. 927, f. 386.

75 Tomás Uribe Márquez, Rebeldía y acción. Al proletariado colombiano, (Bogotá: Editorial Minerva, 1925), 67. Uribe Márquez, quien había residido por algún tiempo en Barcelona, donde estudió y atendió negocios familiares, pasó rápidamente de un liberalismo radical a ser un apasionado impulsor del comunismo y de la acción directa. Ver, María Tila Uribe, Los años escondidos...

${ }^{76}$ Según Torres Giraldo, Olózaga había conocido el marxismo a través de los partidos comunistas de México y Estados Unidos, y había militado en el zapatismo, donde se había impregnado de la tradición anarco-liberal, "todo lo cual lo hacía exponente de los revolucionarios de la época, un partidario decidido de la acción total" (Los inconformes,...739). Esta simpatía por la "acción total" era compartida ampliamente por Tomás Uribe Márquez.
} 
organizarse bajo sus banderas. ${ }^{77} \mathrm{El}$ "Programa del Partido Comunista de Colombia" fueenviadoa diversas localidades junto a un listado de libros que debían constituir la base ideológica de los militantes. ${ }^{78}$ Este proyecto no prosperó, pero la actividad de los dispersos socialistas se acrecentó por esas fechas, haciendo surgir en diversos lugares del país grupos que se aproximaban a la nueva manera de concebir el socialismo. Los socialistas se vieron entonces enfrascados en una carrera vertiginosa por representar la inquietud social y política que los liberales, sumidos en el desconcierto, no atinaban a encuadrar. En medio de su cada vez más exitosa intervención en la arena política, el número de activistas que quiso formar parte de la organización internacional asentada en Moscú no hizo sino acrecentarse. Venciendo las fuertes resistencias que ello suponía, muchos socialistas colombianos se sintieron solidarios con esa organización política transnacional y vincularon a ella el destino de sus organizaciones, pese a no conocerla en detalle.

En esa atmósfera tuvo lugar en julio de 1925 el Segundo Congreso Obrero. Allí los desarticulados grupos socialistas y anarquistas tuvieron una preponderante participación, siendo creada la Confederación Obrera Nacional (CON), que adhirió a la Internacional Sindical Roja (ISR), organización gremial subordinada a la IC. Así, mediante un rodeo, los socialistas colombianos se vincularon a la corriente comunista internacional. ${ }^{79}$

\footnotetext{
77 Torres Giraldo otorga la autoría de ese primer programa comunista a los tres activistas mencionados. Ver: Los inconformes,...743.

78 A.G.N., República, Fondo Ministerio de Gobierno, sección $4^{\mathrm{a}}$, t. 212, ff. 179-182.

79 Torres Giraldo recuerda que el Congreso Obrero había adherido a la Internacional Sindical Roja, "liquidando de paso el frágil vínculo que tenía el Sindicato Central Obrero con la American Federation of Labor de Estados Unidos". Ver: Los inconformes,...783.
} 
En los meses siguientes, sin embargo, las actividades relacionadas con asuntos internacionales fueron extremadamente escasas, reduciéndose a las protestas realizadas en varios lugares del país durante el segundo semestre de 1926 por el juicio seguido a los anarquistas Sacco y Vanzetti en Estados Unidos. ${ }^{80}$ Parece entonces como si esa vinculación de la organización gremial con la corriente comunista hubiera tenido unas consecuencias muy tenues, a juzgar por la reacción despertada entre la mayoría de los delegados al Congreso Obrero, que no fue ni de mucho entusiasmo ni de mucha resistencia, así como por el tipo de discursos y de actividades de los socialistas que durante los años 1925-26 no realizaron casi acciones políticas sino que estuvieron involucrados en huelgas. Fue más bien de los pequeños grupos anarquistas de donde surgió algún comentario, pues en el periódico Vía Libre de Barranquilla hicieron en octubre de 1925 algunas críticas a los "comunistas" que dirigían la CON, "devotos de San Lenin [que] creen que la dictadura roja por ser propiedad de ellos es buena". ${ }^{81}$ A mediados del año siguiente otro grupo anarquista de Bogotá reiteró las críticas a la Revolución Rusa alegando que pese a la legitimidad de la insurrección contra el poder zarista y a la importancia del suceso, la Revolución había fracasado porque no había afianzado la libertad ni —debido a la implantación de la transaccional Nueva Política Económica NEP de Lenin- la igualdad económica. ${ }^{82}$

\footnotetext{
${ }^{80}$ Ignacio Torres Giraldo, Los inconformes, t. 4, ob. cit., p. 877. De otro lado el Sindicato Central Obrero organizó en septiembre de 1926 en Bogotá una manifestación de saludo al pueblo mexicano y al gobierno de Calles, elogiando particularmente sus actitudes anticlericales. "Saludo al pueblo más altivo y musculado del continente", La Opinión, No. 82, septiembre 26 de 1926, Girardot, 3.

81 "Política obrera", Vía Libre, octubre 10 de 1925, Barranquilla.

82 "Del paraíso soviético", Pensamiento y Voluntad, agosto 26 de 1926, Bogotá.
} 
Los anarquistas se hallaban tal vez en mejor posición para conocer los acontecimientos revolucionarios internacionales, pues en esa etapa (1925-1926) mantenían vínculos con grupos del exterior. El Grupo Pensamiento y Voluntad de Bogotá mantuvo relaciones epistolares con los impulsores del periódico anarquista El Sagitario de Tamaulipas (México), y cuando dos europeos afines a sus ideas llegaron al país mantuvieron estrechos vínculos con ellos. Estos eran Juan García, español, y Filippo Colombo, italiano, quienes desde su llegada al país en 1925 realizaron algunas actividades políticas, principalmente en Bogotá. El primero escribió ocasionalmente en los periódicos La Voz Popular y Pensamiento y Voluntad, y los dos participaron en el Congreso Obrero de 1926 como representantes de un grupo obrero de Santa Marta. ${ }^{83}$ Más importante fue la participación de otros anarcosindicalistas españoles e italianos que, pese a residir poco tiempo en la Costa Atlántica, lograron realizar una importante labor de agitación y organización de los trabajadores, la cual tuvo repercusiones especialmente en las plantaciones bananeras de la United Fruit. ${ }^{84}$

Pero aquellos reparos de los anarquistas a la Revolución Rusa contrastaban con la admiración que la

\footnotetext{
83 Ambos fueron expulsados a mediados de 1927 en un momento de agudización de la represión estatal tras la huelga de los trabajadores petroleros en enero de ese año y la amplia huelga de solidaridad que la acompañó. Ver, Expediente relacionado con la expulsión del país de los extranjeros Filippo Colombo y Juan García, A.G.N., República, Fondo Ministerio de Gobierno, sección 4a ${ }^{\text {a t. }}$. 230, ff. 107-136. Sobre su participación en el Congreso Obrero que dio origen al PSR, véase "Ayer se instaló el Tercer Congreso Obrero en el Teatro Bogotá", El Tiempo, noviembre 22 de 1926, Bogotá, 5 .

84 Algunos de los anarcosindicalistas que participaron en actividades políticas en la Costa Atlántica fueron Elías Castellanos, Mariano Lacambra, Abad Lacambra, Genaro Toroni y Juan Candamosa. Véase Carlos Cortés Vargas, Los sucesos de las bananeras, Imprenta de "La Luz", Bogotá, 1929, pp. 9-10, 22, 44 .
} 
mayor parte de los demás socialistas le profesaban. Esto se vio en el Tercer Congreso Obrero Nacional, que acordó en noviembre de 1926 la creación del Partido Socialista Revolucionario (PSR). Este partido reunió básicamente las mismas organizaciones y líderes que formaban la Confederación Obrera Nacional y cristalizó la intensa labor de agitación y organización llevada a cabo por activistas políticos que, no estando ligados orgánicamente entre sí, compartían similares búsquedas y valores políticos. Tres asuntos internacionales habían propuesto para el debate los convocantes a dicho congreso. El primero, acordar si la Federación Obrera Colombia debía "solidarizarse internacionalmente con las organizaciones proletarias en conflicto con la burguesía y en qué forma”. El segundo, decidir "cuál de las internacionales es la que mejor interpreta, abarca y engloba las aspiraciones del proletariado en general, con preferencia desde el punto de vista revolucionario". Y el tercero, en caso de que "el proletariado viera la necesidad de adherirse a una internacional", a cuál de ellas debía hacerlo. ${ }^{85}$

La cuestión de la adhesión a una u otra Internacional tampoco fue esta vez un asunto de gran controversia ni de apasionado interés. Los delegados al III congreso coincidían en la necesidad de vincular la nueva organización a las corrientes socialistas internacionales, y la Confederación Obrera Nacional ya mantenía vínculos con la Internacional Sindical Roja, por lo que resultó muy fácil que desde el momento mismo de su fundación el PSR acordara solicitar su admisión a la IC. ${ }^{86}$ Esa adhesión, de todas maneras, debió suscitar algunas críticas entre los

\footnotetext{
85 "Hoy se reunirá el Tercer Congreso Obrero en Bogotá", El Tiempo, noviembre 21 de 1926, Bogotá, 6. Confederación o Federación Obrera Colombiana eran términos usados indistintamente.

${ }^{86}$ La adhesión a la IC por parte del PSR a partir del momento mismo de su fundación es corroborada por Matallana, delegado colombiano a la Conferencia Comunista de Buenos Aires, y por Torres Giraldo, Los inconformes, t. $4, \ldots 846$.
} 
simpatizantes socialistas, pues Ignacio Torres Giraldo les repuso en enero de 1927 que esa determinación no era hija solamente de una "imitación emulativa". ${ }^{87}$ Pero ella no tuvo al parecer efectos significativos en un primer momento, pues fueron pocos los intercambios entre las dos organizaciones durante el año $1927 \mathrm{y}$ el primer semestre del año siguiente. Aunque uno de los dirigentes socialistas, Moisés Prieto, al parecer estuvo en Moscú en 1926 o 1927 tras haber ido a Europa en viaje de estudio, ello no tuvo repercusiones importantes en el PSR. ${ }^{88}$ En lugar de algún tipo de relación con la IC propiamente, continuaron teniendo contactos con la corriente comunista a través de la $\mathrm{CON}$, la cual mantuvo correspondencia con los organismos satélites de la organización comunista internacional. ${ }^{89}$

Los socialistas colombianos deseaban sin duda integrarse a la Tercera Internacional, pero la forma como entendían esa integración discrepaba de la rigurosa concepción de los bolcheviques. Así, en marzo de 1927 en el periódico La Humanidad, una de las más influyentes publicaciones socialistas, alguien escribió a favor de un "sistema de organización libre" dado que, Colombia "tiene una fisonomía de cierto modo propia y que no es buena táctica imponer predeterminado método usado en otras latitudes (...) somos internacionalistas en doctrina, pero creemos que lo primero es crear y basamentar

\footnotetext{
87 Ignacio Torres Giraldo, "Manifiesto al proletariado colombiano", enero 1 de 1927, Barrancabermeja, en A.G.N., República, Fondo Ministerio de Gobierno, sección $1^{\text {a }}$, t. 982 , f. 415.

${ }^{88}$ Sobre el viaje de Prieto a Europa, ver "Distinguido viajero", La República, noviembre 24 de 1925, Bogotá, 1.

${ }^{89}$ Entre esa correspondencia, la Internacional Juvenil Comunista le envió a mediados de 1927 una encuesta que la CON respondió remitiendo a las "peculiaridades de la sociedad colombiana" (Mauricio Archila, "La otra opinión: la prensa obrera en Colombia 1920-1934", Anuario Colombiano de Historia Social y de la Cultura, No. 13/14, 1986, Bogotá, p. 234).
} 
firmemente la nacionalidad". ${ }^{90}$ En el breve periodo que mediaba entre la fundación del PSR y la escritura de esta carta, los socialistas locales no habían demostrado afán en tener un partido centralizado, firmemente regido por unos principios leninistas, opuesto férreamente a las élites y los partidos locales. Los socialistas colombianos fueron en cambio muy receptivos a las invocaciones antimperialistas de la IC, que encontraban una entusiasta recepción en toda la América Latina. Pero esos llamados no creaban sino que reforzaban el antiguo sentimiento de rechazo a la política hegemónica de Estados Unidos, ampliamente compartido por los sectores populares urbanos politizados.

La Internacional Comunista había enfatizado la cuestión antimperialista por lo menos desde el congreso de la Internacional Sindical Roja de julio de 1924. Y a mediados del año siguiente ya hablaron de tener constituida en Cuba una sección de la Liga Antimperialista de todas las Américas que, con Julio Antonio Mella como secretario, había realizado una gran actividad y establecido contactos con diversos grupos de la región. ${ }^{91}$ Ese grupo estudiantil dirigido por Mella al parecer entró en contacto en 1926 con la CON para interesarla en sus actividades, por lo cual fue organizada la sección colombiana de la Liga Antimperialista, la cual realizó a partir del segundo semestre de 1926 diversas labores de propaganda. ${ }^{92}$ Los socialistas estuvieron muy activos en campañas contra la intervención en Nicaragua, prestaron particular atención a las conferencias panamericanas en las que bajo el control de Estados Unidos periódicamente participaban los gobiernos latinoamericanos, y fueron

\footnotetext{
${ }_{90}$ La Humanidad, marzo 15 de 1927, Cali, citado por Mauricio Archila en "La otra opinión: la prensa obrera en Colombia 1920-1934", ob. cit., p. 234. 91 "Bolshevik aims, and policies in Mexico and Latin America", enero 12 de 1927, en A.G.N., FMRE, UADC, t. 8, cp. 126, c. 332, ff. 124-128.

${ }^{92}$ Ignacio Torres Giraldo, Los inconformes, t. 3,...813.
} 
sensibles a la causa independentista de los cubanos. ${ }^{93}$ El repudio a la intervención militar estadounidense en Nicaragua fue particularmente intenso. La amplitud de la simpatía hacia la causa del rebelde general Sandino fue tal que el 22 de enero de 1927 se realizó en Bogotá una manifestación en la que tomaron parte no sólo los socialistas sino incluso liberales y conservadores. ${ }^{94} \mathrm{~A}$ comienzos de 1927, además de actividades de protesta por esa intervención —que se realizaron en lugares tan diversos como Santa Marta, Buenaventura y Barranquilla - hubo en varias regiones del país huelgas de solidaridad con las protestas de los trabajadores de la empresa petrolera estadounidense Tropical Oil de Barranca. $^{95}$

El antimperialismo fue un elemento importante de la identidad socialista. Armonizaba con la inclinación nacionalista de sus pretensiones revolucionarias, que los llevó a tratar de acomodar su proyecto a las particularidades colombianas. Torres Giraldo, por ejemplo, escribió que "no pudiéndose hacer la revolución simultáneamente en todos los países, deberán necesariamente prepararse cada uno de ellos dentro de su fisonomía nacional, para desenvolverse de conformidad con los factores, circunstancias y oportunidades que se

\footnotetext{
93 Sobre las actividades antimperialistas, Ignacio Torres Giraldo, Los inconformes, t. $4, \ldots 877$ y 904-906, 924-926.

94 "La manifestación antiimperialista de hoy", El Tiempo, enero 22 de 1927, Bogotá, 5. Igualmente fue promovida la vinculación de un contingente de colombianos al pequeño ejército de Sandino ("Cuarenta colombianos acompañan a Sandino", El Socialista, julio 29 de 1928, Bogotá; Ignacio Torres Giraldo, Los inconformes, ob. cit., t. 4, pp. 905, 925; carta de Ignacio Torres Giraldo a los miembros del periódico La Humanidad, Cali, en José María Rojas, La estrategia insurreccional socialista y la estrategia de contención del conservatismo doctrinario, t. 1, informe académico mecanografiado, Cali, 1989, p. 188).

95 "Se verificó la gran manifestación antiyanqui", $A B C$, enero 27 de 1927, Quibdó, p. 1; "Los obreros de Ciénaga se solidarizan con el boicoteo a la Tropical Oil Co.", El Gladiador, febrero 3 de 1927, Honda.
} 
presenten" ${ }^{96} \mathrm{El}$ comunismo, pues, resultaba atractivo a los socialistas colombianos por su énfasis antimperialista tanto quizás como por su énfasis en la igualdad social. En sus documentos y acciones, el internacionalismo parece estar menos guiado por una afinidad con los proletarios del mundo explotados por el capitalismo que por una cercanía con las naciones dominadas por una potencia extranjera, y especialmente con los países latinoamericanos agredidos de alguna forma por Estados Unidos. ${ }^{97}$ A propósito el mismo Torres Giraldo escribirá años después, que el antimperialismo del PSR había en ocasiones aparecido con "acento patriotero, como simple resentimiento anti-yanki". ${ }^{98}$

Como heindicado, los líderes socialistas mantuvieron contacto con la Internacional Comunista inicialmente a través de cartas con la Internacional Sindical Roja. El Comintern, sin embargo, durante el primer año y medio de vida del partido colombiano materializó su influjo también a través de las publicaciones que difundían sus preceptos, los cuales devinieron un punto de referencia central para aquellos. ${ }^{99} \mathrm{Y}$ a mediados de 1928 entraron en una nueva etapa los vínculos entre el PSR y la IC,

\footnotetext{
${ }^{96}$ Carta al Camarada Jorge Cárdenas, febrero 22 de 1928, en La estrategia insurreccional socialista, t. 1,... 197.

97 Torres Giraldo intentó convencer en febrero de 1928 a otros dirigentes socialistas de la conveniencia de impulsar "un organismo vasto que englobe una alianza de todas las tendencias sinceramente revolucionarias de la América Latina, capaz de contrarrestar el Pan-Americanismo." Ciertas alusiones al sentimiento indo-hispano recuerdan al APRA. Ver José María Rojas, La estrategia insurreccional socialista, t. 1,... 197-198.

${ }^{98}$ Ignacio Torres Giraldo, Los inconformes, t. 3,...813.

${ }^{99} \mathrm{El}$ interés por los problemas internacionales se expandió considerablemente durante este periodo, como lo indica el hecho de que en Rionegro, pequeña aunque dinámica población cafetera de Santander, algunos dirigentes locales mantuvieran correspondencia con México, Barcelona y Rusia. Ver Diana Lorenza Piedad Jaimes, Trabajadores ferroviarios y conflicto social en Santander (1926-1930): levantamiento de La Gómez en 1929, monografía historia Universidad Industrial de Santander, Bucaramanga, 1995, 147148.
} 
pues esta en su sexto congreso, realizado entre julio y septiembre de 1928, admitió en su seno a siete nuevas organizaciones de diversas partes del mundo, entre ellas el PSR de Colombia. Esa admisión constituía una concesión, pues desde el punto de vista de los bolcheviques aquel no era todavía "por su estructura y su ideología" un partido enteramente comunista. Por ello desde Moscú debía recibir "las directivas, los consejos y la ayuda necesaria" para que, "transformando y afianzando sus organizaciones, elevando su nivel ideológico, forjando su conciencia de clase, conservando siempre y reforzando aún mucho más su carácter de partido de masas", se convirtiera en un auténtico partido leninista. ${ }^{100} \mathrm{La}$ IC en realidad tutelaba de manera estrecha y permanente a todos sus partidos filiales, a los que durante este periodo presionó para que se bolchevizaran, rompiendo con sus particulares tradiciones nacionales. ${ }^{101}$

Dado el carácter de la Internacional Comunista, se suponía que su activa intervención en los asuntos internos de los partidos afiliados no era una molestia a tolerar sino un factor esencial para su pleno desarrollo. La amplia injerencia anunciada para el PSR suponía la conformidad de los socialistas colombianos a esa subordinación. Pero, ¿estos eran conscientes del tipo de relación que implicaba la pertenencia a la IC? ¿Esa pertenencia cambió las concepciones o las actividades de los socialistas colombianos, que, como ya hemos señalado habían no sólo manifestado su adhesión a los

\footnotetext{
${ }^{100}$ Citado en Ignacio Torres Giraldo, Los inconformes, t. 4, ob. cit., p. 941 . El delegado de la IC en Colombia, Rabaté, consideró que la adhesión del PSR no había estado motivada por el deseo de "modificar su ideología y encuadrar su acción táctica en los dictados del Comintern", sino para ampararse en su prestigio, "verse apoyado por el movimiento comunista mundial, para tomar el poder y luego no seguir el camino que le trace". "La masacre de las bananeras", Teoría y práctica, No.14, abril de 1979, Bogotá, 24.

${ }^{101}$ Para el caso francés, véase Stéphane Courtois y Marc Lazar, Histoire du Parti communiste français, $2^{\mathrm{a}}$ ed., PUF, París, 2000, espec. pp. 83-118.
} 
principios de la organización comunista internacional sino que mantenían intercambios con ella? Desde antes que la IC admitiera al PSR los dirigentes de éste habían sido atraídos fuertemente por el comunismo, pese a que prácticamente ningún militante socialista había por entonces conocido la Unión Soviética y que ningún miembro del Comintern había estado en Colombia. ${ }^{102}$ Además de la lectura de breves textos políticos de los jefes bolcheviques y de los manuales de comunismo y marxismo, ellos habían podido conocer las actividades y concepciones de la IC a través de algunas de sus publicaciones y documentos. ${ }^{103} \mathrm{La}$ Correspondencia Sudamericana (junio de 1926 a septiembre de 1927 y agosto de 1928 a mayo de 1930) e Imprecorr (a partir de 1928) fueron publicadas en español, y es posible que algunos números de esas revistas hubieran circulado en Colombia. ${ }^{104}$

A partir de la inclusión del PSR en la IC, los vínculos entre las dos organizaciones se incrementaron, desarrollándose mediante tres mecanismos: el envío de

${ }_{102}$ Algunos líderes se percibían como parte de la tradición socialista universal. Neftalí Arce, quien había estudiado medicina en Francia, escribió a mediados de 1927 que "el socialismo revolucionario era la expresión de la tradición socialista europea desde Babeuf hasta Marx y Lenin, pasando por Saint Simon, Proudhon y Luis Blanc". La Humanidad, junio 19 de 1927, Cali, citado en Mauricio Archila, Cultura e identidad obrera. Colombia 1910-1945, (Bogotá: Cinep, 1991),264.

${ }^{103}$ En 1925 los promotores de un no materializado Partido Comunista habían recomendado la lectura de una quincena de obras, algunas relacionadas directamente con la IC. "Partido Comunista de Colombia", A.G.N., República, Fondo Ministerio de Gobierno, sección 4a , t. 212, ff. 179-182.

104 Manuel Caballero, La Internacional Comunista y la revolución latinoamericana, ob. cit., pp. 236-237. Caballero plantea que los análisis aparecidos en las publicaciones de la IC sobre la situación de sus partidos filiales de América Latina servían, no tanto para guiar a esos partidos, como para "dar al movimiento comunista internacional una imagen particular de América Latina". 
emisarios de la IC, los viajes de dirigentes colombianos a la Unión Soviética y a eventos de la IC en otros países, y, en tercer lugar, mediante la correspondencia. Respecto al primer mecanismo, sólo un delegado de la Internacional Comunista estuvo en Colombia antes de $1930 .{ }^{105} \mathrm{El}$ francés Octave Rabaté, representante de la Internacional Sindical Roja, y por lo tanto de la IC, que llegó a Bogotá a mediados de 1928 en un momento de gran agitación social y política pues el congreso discutía la llamada ley heroica, que pretendía darle al gobierno fuertes poderes destinados a combatir la amenaza comunista, y que tanto los socialistas como los liberales vieron como una legislación atentatoria contra las libertades públicas. Los socialistas canalizaban la inconformidad social y preparaban la huelga de las bananeras, y Rabaté contribuyó a establecer una alianza con los liberales para oponerse a aquella ley, pero se mantuvo más bien expectante ante los planes insurreccionales de los socialistas. ${ }^{106}$

El segundo tipo de intercambio fueron los viajes a los eventos organizados por la IC, como las conferencias sindical y comunista en Montevideo y Buenos Aires a mediados de 1929. Aquí también están incluidos los peregrinajes a la capital mundial del comunismo, más importantes aún. El primer viaje institucional de

\footnotetext{
${ }^{105}$ Aparte de los funcionarios de la IC, tal vez el único extranjero que estuvo ligado sólidamente al PSR fue el boliviano González Arce, quien trabajó activamente muy cerca de Torres Giraldo, principalmente en Medellín. Véase Ignacio Torres Giraldo, Los inconformes, t. 4,...878.

${ }^{106}$ Klaus Meschkat y José María Rojas, comps., Liquidando el pasado. La izquierda en los archivos de la Unión Soviética, (Bogotá: Fescol / Taurus, 2009), 141; Ignacio Torres Giraldo, Los inconformes, t. 4,...932-933; "La masacre de las bananeras", ob. cit., p. 12. Un segundo emisario de la IC estuvo en Colombia durante este tiempo, el norteamericano James Harfield, que se hizo conocer como Jaime Nevárez. Pero no era propiamente un delegado del Comintern. Klaus Meschkat y José María Rojas, comps., Liquidando el pasado,...122.
} 
socialistas colombianos a Moscú tuvo lugar a comienzos de 1928 y en él tomaron parte Alberto Castrillón de Bogotá, junto a Neftalí Arce y Jorge Cárdenas de Cali, como delegados al cuarto congreso de la organización sindical mundial de los comunistas. Casi al mismo tiempo el PSR comisionó al joven estudiante Guillermo Hernández Rodríguez para que asistiera a las festividades del décimo aniversario de la Revolución Rusa y para que tramitara la admisión del PSR en la IC. ${ }^{107}$ Cerca de un año más tarde otro dirigente socialista, Ignacio Torres Giraldo, tras la represión de la huelga de las bananeras, realizó el mismo viaje, permaneciendo en Moscú durante largos meses. ${ }^{108}$ Más allá de los objetivos específicos, esas visitas, comunes para los dirigentes comunistas de todo el mundo, eran la oportunidad para el re-conocimiento de la experiencia que se estaba desarrollando en Rusia, y para la asimilación directa del socialismo tal como lo concebían los soviéticos. Este era un mecanismo de propaganda al que los dirigentes rusos prestaban mucha atención, pues a través de él embebían a los visitantes en el espíritu y la doctrina bolchevique sin que ello procediera como una mera manipulación, pues los viajeros iban con la actitud de quien hace un viaje iniciático.

Esos viajes representaron un avance significativo en la formación de un pequeño grupo de líderes dentro de las concepciones bolcheviques. Su contacto directo con la "patria de la revolución" los habilitaría para reemplazar a los antiguos dirigentes socialistas y establecería una ruptura neta en la forma de concebir el socialismo, amoldándose a las normas y valores de la Tercera Internacional. Hernández Rodríguez a su regreso de la Unión Soviética coordinó la fundación del Partido Comunista de Colombia PCC, fue su secretario

\footnotetext{
${ }^{107}$ Klaus Meschkat y José María Rojas, comps., Liquidando el pasado,...24, 93, 104; Ignacio Torres Giraldo, Los inconformes, t. 4,...933. Moisés Prieto había estado en Moscú hacia 1927, aunque al parecer por cuenta propia.

108 Torres Giraldo permaneció más de cuatro años allí. Véase Ignacio Torres Giraldo, Anecdotario, Universidad del Valle, Cali, 2004, 159-182.
} 
general y el hombre clave de la IC en el país durante algunos años. Ignacio Torres Giraldo, según testimonió en su Anecdotario, transformó sustancialmente su concepción política, y tras imbuirse de las concepciones soviéticas volvió al país para engrosar las filas del Partido Comunista, en el cual llegaría a ser secretario general. Alberto Castrillón, quien hizo agrios reparos a la IC a comienzos de 1929, fue lanzado en febrero del año siguiente como candidato presidencial del PSR y luego estuvo entre los iniciadores del Partido Comunista, tras haber presentado disculpas por aquellas acusaciones. ${ }^{109}$

Tales traslados guardaban, no obstante, poca relación con la abundancia de recursos que supuestamente invertían desde Moscú en promover la revolución mundial, como algunos conservadores lo presumían. El "oro de Moscú" benefició poco a Torres Giraldo, por ejemplo, quien destaca en el relato de su viaje a la capital soviética las privaciones a que se enfrentó. Tampoco a Alberto Castrillón, quien a su regreso de Moscú en 1928 debió ir al consulado de Colombia en Berlín a solicitar ayuda para poder continuar su viaje a Colombia. ${ }^{110}$ Poco interés tenía la IC en atender una sección como la colombiana con poca importancia dentro de su rango de prioridades.

\footnotetext{
${ }^{109}$ Segunda carta de la IC al PSR, febrero de 1930, transcrita en Julio Cuadros Caldas, Comunismo criollo, t. 1, ob. cit., pp. 360-388; Ignacio Torres Giraldo, Los inconformes, t. 4,...1007. Torres Giraldo dice que Castrillón fue "leal defensor del pensamiento revolucionario internacional y de la Unión Soviética" (t. 4, p. 1006). De la evolución política de Nefatlí Arce y Acosta no tenemos datos.

${ }^{110}$ Ignacio Torres Giraldo, Anecdotario,...139. Sobre el viaje de Castrillón y su solicitud de ayuda al consulado, la cual le fue negada, ver José María Rojas, La estrategia insurreccional socialista, t. 1,...213-216. Las pertenencias de Castrillón consistían básicamente en medallas, efigies y cuadernos de notas de Moscú, lo cual en palabras de un diligente funcionario de aduanas probaba que el ministro de Guerra "anda acertado al señalar nación con valerosa energía peligro comunistas". Véase La estrategia insurreccional socialista, t. $1, \ldots .217-224$.
} 
La tercera forma de relación fue la correspondencia, mediante la cual la IC conocía la situación colombiana y daba instrucciones sobre la manera de actuar. El PSR le envió una carta recién sucedida la huelga de las bananeras (diciembre de 1928) en la que relataba los hechos y hacía un balance de la situación. Su respuesta apareció publicada en la revista del Secretariado Suramericano (Correspondencia Sudamericana de mayo del año siguiente), pero en junio de 1929 durante la Conferencia Comunista de Buenos Aires los delegados colombianos todavía no la conocían. En febrero de 1930 una segunda carta de la IC reclamó a los dirigentes del PSR que la primera carta aún no había sido dada a conocer al partido. La carta seguramente había llegado a manos de algún dirigente que, estando enfrascado como los demás en los preparativos insurreccionales, no la dio a conocer más que a sus allegados, no así entre las instancias pertinentes.

Las cartas desde Moscú fueron pocas pero tienen un notable interés para discernir mejor el curso del PSR. Ayudan a comprender el camino que tomó durante la fase en que habiendo acopiado una alta capacidad de movilización y habiendo obtenido simpatía entre vastos grupos de trabajadores, se lanzó por el camino de la insurrección. Esas comunicaciones dejan ver cómo se ponen en juego los estatus de uno y otro: el partido colombiano asume el rol del alumno que recibe de sus tutores bolcheviques la línea de acción a seguir: la IC le indica los tipos de organización que debe crear, el tipo de reclamos que debe levantar, los mecanismos de alianza que debe establecer. Pero la institución maestra no le prescribe la estrategia insurreccional ni le da instrucciones específicas acerca de cómo organizarse para ello. De hecho, la IC fue puesta en julio de 1928 ante el hecho consumado del proyecto insurreccional, 
en un momento en que ni siquiera había admitido en su seno al PSR. Además, como recuerda Torres Giraldo, desde mediados de 1927 ya había dirigentes socialistas interesados en la fabricación de bombas y en abril de 1928 ya estaba concebido el plan completo de insurrección, que sería intentado de diversas maneras. ${ }^{111} \mathrm{~A}$ pesar de todo esto, el recurso de la insurrección halló impulso en las concepciones y demandas de la IC a sus partidos miembros, pues les exigía contar con un organismo clandestino paralelo, y más globalmente los imbuía del carácter inexorablemente violento de los cambios, contenido en la ciencia de la revolución. ${ }^{112}$

La soñada insurrección fracasó rotundamente por su propio despropósito y por la represión del gobierno, naufragando con ella las ilusiones de tomarse el poder. El PSR quedó entonces abocado a su práctica disolución, un desastre del que varios socialistas responsabilizaron a la IC. ${ }^{113}$ Moisés Prieto y Heraclio Matallana dijeron en Buenos Aires que las dificultades por las que pasaba el partido se debían tanto a la represión oficial como al olvido en que la IC los había tenido, a su falta de apoyo en el momento crucial de lucha por el que habían

\footnotetext{
${ }_{111}$ Ignacio Torres Giraldo, Los inconformes, t. 4, ob. cit., pp. 928-934. La IC conoció al menos desde 1928 los preparativos insurreccionales, pues su delegado participó en una reunión de revolucionarios colombianos y venezolanos que discutieron planes militares conjuntos. "La masacre de las bananeras",...27.

${ }^{112}$ La tercera de las 21 condiciones que un partido debía llenar para ser aceptado en la IC, era la "constitución de un aparato organizativo paralelo, o sea, clandestino". Ver Manuel Caballero, La Internacional Comunista y la revolución latinoamericana,...27.

113 Alberto Castrillón - uno de los principales líderes socialistas, y quien había visitado Moscú - afirmó en febrero de 1929 en una carta a la IC que esta, al aceptar al PSR como una de sus secciones, había cometido "un error y un crimen". Ver segunda carta de la IC al PSR, febrero de 1930, transcrita en Julio Cuadros Caldas, Comunismo criollo, t. 1,...384.
} 
atravesado. ${ }^{114}$ Desde esta perspectiva sobrevaloraban las posibilidades de intervención de la IC, pues habían esperado que en el momento decisivo ella diera soluciones o recursos para culminar exitosamente la acción militar. Pero la IC estaba en general poco interesada en dar más que dirección política, encaminando a los partidos hacia una estructura y una concepción adecuada, según los cánones leninistas, para tomarse el poder con base en sus propias fuerzas. ${ }^{115}$

En vista del ideario bolchevique, los socialistas no avanzaron mucho en asimilar el conjunto discursivo leninista ni en lograr que sus simpatizantes percibieran el mundo social como irreductiblemente dividido entre burgueses y proletarios, ni en que concibieran el comunismo como una fase superior del desarrollo de la humanidad. Tampoco lograron constituir un partido centralizado, homogéneo ideológicamente. El PSR logró en cambio movilizar amplios grupos de trabajadores para reclamar mejores condiciones laborales, logró dinamizar la oposición al gobierno conservador, logró que grupos importantes de población se introdujeran en la escena política. Igualmente permitió a un significativo grupo de activistas políticos de origen humilde conectarse con el mundo y sus alternativas políticas y culturales. Los dirigentes del PSR creyeron que la IC había hecho una contribución fundamental a los logros del partido colombiano. Gran parte de ellos no la culparon de su fracaso sino que por el contrario le reclamaron una

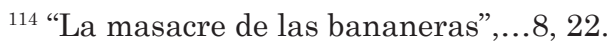

${ }^{115}$ La IC no se comprometió ampliamente en las actividades de los partidos latinoamericanos salvo en el caso brasileño, durante el fallido levantamiento de Luis Carlos Prestes en 1935. Su intervención, con algunos emisarios en labores de asesoría y en la coordinación del Secretariado Sudamericano, se hizo de manera discreta, sin que la estructura en Moscú se implicara grandemente, y sin comprometer recursos importantes. Manuel Caballero, La Internacional Comunista y la revolución latinoamericana,... 47-66, 163178.
} 
intervención más contundente. Así lo expresó Raúl Eduardo Mahecha en Buenos Aires: la Internacional Comunista debe "intervenir en las cosas de nuestro Partido y poner un poco de orden. Necesitamos que se nos ayude", dijo. ${ }^{116}$

La IC pudo entonces intervenir sin obstáculos cuando el PSR agonizaba, encargando a un grupo de activistas capacitados en Moscú de fundar sobre las ruinas de su filial colombiana un "auténtico" partido comunista.${ }^{117}$ Los antiguos líderes aceptaron cabizbajos la reorientación, no sólo debido a que estaban arrinconados por la represión dirigiendo un partido que no era más que la sombra de sí mismo. También lo hicieron porque su propio fracaso parecía realzar la fatuidad de sus pretensiones de darle al partido colombiano ciertos rasgos que correspondieran con las particularidades locales, en contra de las prescripciones de Moscú. Había que aceptar con humildad que la Comintern gestionara los asuntos de un partido que había aceptado ser una sucursal de un proyecto de emancipación universalista. La IC era la cabeza de un cuerpo constituido por los partidos revolucionarios del mundo entero: esa era una idea que circulaba entre los socialistas colombianos desde que habían comenzado a buscar que los admitieran en aquella organización. "El ideal del obrerismo está muy por encima de las ambiciones parroquiales; tiene toda la fogosidad de la juventud y de todo nuevo apostolado y de ahí que sus aspiraciones se extiendan a dominar, no en Honda, ni en Colombia, es la hegemonía universal lo que persigue", había escrito un desconocido activista en 1924. Y el conocido dirigente socialista Tomás Uribe Márquez había exaltado el objeto de la Internacional Comunista diciendo que ella pretendía que la humanidad fuera "una

\footnotetext{
116 "La masacre de las bananeras",...22.

${ }^{117}$ Klaus Meschkat y José María Rojas, comps., Liquidando el pasado, ob. cit., p. 415; Ignacio Torres Giraldo, Los inconformes, t. 4,...1016-1017.
} 
genuina comunidad con un propósito orgánico común: la justicia que predicaron Jesús, Marx, Engels, Rosa Luxemburgo, Lenin y otros". ${ }^{118}$ Ese ideal de humanidad debía sobreponerse, es más, debía borrar la noción de patria nacional. Así lo indicó el mismo Uribe Márquez al decir que en las sociedades capitalistas la patria era una mentira, puesto que bajo el dominio del capital "no puede haber patria" dado que allí los propietarios se asocian para erigir un Estado que no se ocupa sino de preservar sus privilegios. La patria, además, era un instinto primitivo y una idea egoísta, que menoscababa el "amor al semejante, es decir, a la humanidad”. El proletariado, añadió, sólo tendría patria cuando se adueñara del poder y lo ejerciera enteramente en su propio país. En lugar de esa patria propia de la "democracia burguesa", la organización comunista transnacional hermanaría a los humanos "por encima de las patrias, en el apostolado y en la lucha". ${ }^{119}$ Pero la vocación del ideal comunista no era crear un conjunto de patrias o de naciones sino abolirlas para levantar de las ruinas del capitalismo una "única patria, la patria proletaria", cuya avanzada y anticipación era la Unión Soviética, como lo expresó María Cano en 1930. ${ }^{120}$

\section{El mundo en cada corriente}

Se podría buscar en agentes "externos" el factor clave de la introducción o la ausencia de ciertas ideas en Colombia. Entre 1904 y 1930 no más de una veintena de colombianos ligados a organizaciones obreristas o socialistas viajó al exterior y un número similar de extranjeros ligados a grupos socialistas, anarquistas o

\footnotetext{
118 José Vicente Ramírez, "La cuestión social. Réplica a un artículo de don A. Vanegas", El Motor, agosto 23 de 1924, Honda.

119 Tomás Uribe Márquez, Rebeldía y acción,...47, 35, 39, 41, 67.

${ }^{120}$ Carta de 1930, en Ignacio Torres Giraldo, María Cano, mujer rebelde, Publicaciones de La Rosca, Bogotá, 1972, 167.
} 
comunistas estuvo en el país. De estos fue aún menor el número de quienes desarrollaron intensamente algún tipo de activismo político. ${ }^{121} \mathrm{Si}$ se hace una comparación con la mayor parte de los países latinoamericanos, se constata que su volumen fue insignificante, siendo además su participación en las diversas organizaciones obreristas y socialistas muy marginal. Ellos ayudaron a difundir las ideas novadoras aunque sin alcanzar un rol destacado, pero la escasez o la abundancia de inmigrantes no podría explicar de ningún modo la flaqueza o el vigor de una corriente o doctrina política. Responder a esa cuestión implica ocuparse de la naturaleza de una sociedad y un régimen político específicos, los cuales fueron acomodando los impulsos externos a la fisonomía que ya los caracterizaba. Pero decir esto no deja de ser problemático, pues resulta arriesgado separar lo intrínseco y lo externo a una sociedad y a un régimen político que, como el colombiano, han permanecido en un ininterrumpido contacto con las ideas, las sensibilidades, las prácticas políticas del mundo occidental. Establecer nítidamente un afuera sería posible si hubiera un momento en que Colombia se hubiera quedado al margen del ámbito en que se desplegaba la política intelectual de occidente. Pero esto que se dice respecto al socialismo es igualmente pertinente respecto al liberalismo, el conservatismo, el republicanismo y demás corrientes políticas, que nunca desearon sustraerse a la experiencia del mundo.

Cosa distinta es la manera como desde cada corriente política ha sido concebido el mundo y el lugar que en él se han dado y le han dado a la nación colombiana. En el caso de los grupos obreristas y socialistas, este periodo fue testigo del tránsito de una inscripción ardiente en la patria nacional - que remitía a la Revolución Neogranadina y una república democrática en la cual la exigencia de igualdad era compatible con la pluralidad social- a su inscripción en un ideal de humanidad regido por el imperativo bolchevique de construir un orden social

${ }^{121}$ Véanse los cuadros al final. 
Patriotismo o universalismo proletario. El lugar del mundo en el obrerismo y el socialismo colombiano, 1904-1930

uniclasista guiado por el partido revolucionario mundial, que por lo tanto demandaba la abolición de las naciones. La simpatía de los socialistas revolucionarios por esta pretensión no entrañaba un choque entre una tradición nacional y otra externa sino más bien un choque entre una tradición republicana ya asentada y formas inéditas de radicalismo político que sólo lograron atraer a una muy pequeña parte de la ciudadanía.

Cuadro 1. Líderes socialistas u obreristas colombianos que viajaron al exterior.

\begin{tabular}{|c|c|c|c|}
\hline Nombre & $\begin{array}{c}\text { Lugar } \\
\text { visitado }\end{array}$ & Fecha & Motivo \\
\hline $\begin{array}{l}\text { Francisco de } \\
\text { Heredia }\end{array}$ & Londres & $1907-08$ & Estudios \\
\hline Diodoro Sánchez & Europa & $1908-11$ & $\begin{array}{l}\text { Según un } \\
\text { apologista, dar "su } \\
\text { vuelta al mundo" }\end{array}$ \\
\hline Emilio Murillo & $\begin{array}{l}\text { Estados } \\
\text { Unidos }\end{array}$ & 1910 & $\begin{array}{l}\text { Actividades } \\
\text { musicales y negocios }\end{array}$ \\
\hline $\begin{array}{l}\text { Vicente Olarte } \\
\text { Camacho }\end{array}$ & Europa & 1912 & $\begin{array}{l}\text { Conocer actividades } \\
\text { y leyes obreras }\end{array}$ \\
\hline $\begin{array}{l}\text { José Marcelino } \\
\text { Castro }\end{array}$ & Europa & 1910's & \\
\hline $\begin{array}{l}\text { Carlos Julio } \\
\text { Carreño }\end{array}$ & Europa & 1910's & $\begin{array}{l}\text { Actividades } \\
\text { comerciales }\end{array}$ \\
\hline $\begin{array}{l}\text { Pepe Olózaga } \\
\text { Betancur "Dimitri } \\
\text { Ivanovich" }\end{array}$ & México & 1910's & Militante zapatista \\
\hline $\begin{array}{l}\text { Tomás Uribe } \\
\text { Márquez }\end{array}$ & $\begin{array}{l}\text { Barcelona } \\
\text { México }\end{array}$ & 1910’s & Estudios agronomía \\
\hline Biófilo Panclasta & Europa & 1910’s & $\begin{array}{l}\text { Actividades } \\
\text { políticas }\end{array}$ \\
\hline $\begin{array}{l}\text { Campo Elías } \\
\text { Calderón }\end{array}$ & $\begin{array}{l}\text { Estados } \\
\text { Unidos }\end{array}$ & 1910's & \\
\hline Jacinto Albarracín & $\begin{array}{l}\text { Estados } \\
\text { Unidos }\end{array}$ & 1920 & $\begin{array}{l}\text { III Congreso Obrero } \\
\text { Panamericano }\end{array}$ \\
\hline
\end{tabular}




\begin{tabular}{|c|c|c|c|}
\hline Nombre & $\begin{array}{l}\text { Lugar } \\
\text { visitado }\end{array}$ & Fecha & Motivo \\
\hline $\begin{array}{l}\text { Luis Enrique } \\
\text { Osorio }\end{array}$ & $\begin{array}{l}\text { Buenos } \\
\text { Aires }\end{array}$ & 1922 & Dramaturgia \\
\hline Neftalí Arce & $\begin{array}{l}\text { París } \\
\text { Moscú }\end{array}$ & $\begin{array}{l}1920 ’ \mathrm{~s} \\
1928\end{array}$ & $\begin{array}{l}\text { Estudios de } \\
\text { medicina } \\
\text { Establecer } \\
\text { relaciones con la IC }\end{array}$ \\
\hline Jorge Cárdenas & Moscú & 1928 & $\begin{array}{l}\text { Establecer } \\
\text { relaciones con la IC }\end{array}$ \\
\hline Moisés Prieto & $\begin{array}{l}\text { Europa - } \\
\text { Moscú } \\
\text { Buenos } \\
\text { Aires }\end{array}$ & $\begin{array}{l}1925-27 \\
1929\end{array}$ & $\begin{array}{l}\text { Estudios - Política } \\
\text { socialista } \\
\text { Conferencia } \\
\text { Comunista } \\
\text { Latinoamericana }\end{array}$ \\
\hline $\begin{array}{l}\text { Guillermo } \\
\text { Hernández } \\
\text { Rodríguez }\end{array}$ & Moscú & $1928-30$ & $\begin{array}{l}\text { Establecer } \\
\text { relaciones con la IC }\end{array}$ \\
\hline Alberto Castrillón & Moscú & 1928 & $\begin{array}{l}\text { Establecer } \\
\text { relaciones con la IC }\end{array}$ \\
\hline Fideligno Cuéllar & Montevideo & 1929 & $\begin{array}{l}\text { Conferencia sindical } \\
\text { de la IC }\end{array}$ \\
\hline $\begin{array}{l}\text { Raúl Eduardo } \\
\text { Mahecha }\end{array}$ & $\begin{array}{l}\text { Buenos } \\
\text { Aires }\end{array}$ & 1929 & $\begin{array}{l}\text { Conferencia } \\
\text { Comunista } \\
\text { Latinoamericana }\end{array}$ \\
\hline Heraclio Matallana & $\begin{array}{l}\text { Buenos } \\
\text { Aires }\end{array}$ & 1929 & $\begin{array}{l}\text { Conferencia } \\
\text { Comunista } \\
\text { Latinoamericana }\end{array}$ \\
\hline $\begin{array}{l}\text { Ignacio Torres } \\
\text { Giraldo }\end{array}$ & Moscú & $1929-34$ & $\begin{array}{l}\text { Aprendizaje } \\
\text { comunismo }\end{array}$ \\
\hline
\end{tabular}

Fuentes: La Libertad, septiembre 10 de 1912, Bogotá; El Ariete, marzo 12 de 1911, Bogotá; Chantecler, octubre 9 de 1910, Bogotá; La Libertad, mayo 3 de 1913, Bogotá; Julio César Acelas, Obreros y artesanos de Bucaramanga, p. 251; Ignacio Torres G., Los inconformes, t. 3, pp. 720, 739-740, t. 4, p. 990; María Tila Uribe, Los años escondidos, pp. 75-77; La Civilización, enero 27 de 1910, Bogotá; El Tiempo, diciembre 26 de 1922, Bogotá, p. 3; Klaus Meschkat y José María Rojas, Liquidando el pasado, espec. pp. 104, 106107, 191-192, 216, 235, 259; Ignacio Torres Giraldo, Anecdotario, pp. 159182. 
Patriotismo o universalismo proletario. El lugar del mundo en el obrerismo y el socialismo colombiano, 1904-1930

Cuadro 2. Extranjeros participantes en actividades socialistas u obreristas.

\begin{tabular}{|c|c|c|c|c|}
\hline Nombre & Año & País & $\begin{array}{c}\text { Actividad } \\
\text { desarrollada }\end{array}$ & $\begin{array}{c}\text { Lugar } \\
\text { actividad }\end{array}$ \\
\hline $\begin{array}{l}\text { Julián J. } \\
\text { Cubellos }\end{array}$ & 1910,15 & & $\begin{array}{l}\text { "Conferencias } \\
\text { anarquistas" }\end{array}$ & Barranquilla \\
\hline $\begin{array}{l}\text { Pedro } \\
\text { González } \\
\text { Blanco }\end{array}$ & 1911 & España & $\begin{array}{l}\text { Conferencias } \\
\text { defendiendo el } \\
\text { liberalismo y } \\
\text { estimulando la } \\
\text { organización } \\
\text { obrera }\end{array}$ & $\begin{array}{l}\text { Bogotá, } \\
\text { Zipaquirá }\end{array}$ \\
\hline $\begin{array}{l}\text { Ángel } \\
\text { Domingo } \\
\text { Beroes }\end{array}$ & 1912 & Venezuela & $\begin{array}{l}\text { Dirección } \\
\text { periódico El } \\
\text { Artesano }\end{array}$ & Cúcuta \\
\hline $\begin{array}{l}\text { Vicente } \\
\text { Adamo }\end{array}$ & $1915-26$ & Italia & $\begin{array}{l}\text { Dirección luchas } \\
\text { agrarias }\end{array}$ & Córdoba \\
\hline $\begin{array}{l}\text { Nicolás } \\
\text { Gutarra }\end{array}$ & $1920-24$ & Perú & $\begin{array}{l}\text { Organización } \\
\text { Liga de } \\
\text { inquilinos }\end{array}$ & Barranquilla \\
\hline $\begin{array}{l}\text { Silvestre } \\
\text { Savitsky }\end{array}$ & $1921-25$ & Rusia & $\begin{array}{l}\text { Grupo de estudio } \\
\text { Luis Tejada }\end{array}$ & Bogotá \\
\hline $\begin{array}{l}\text { Rodolfo Von } \\
\text { Wedell }\end{array}$ & 1924 & Alemania & $\begin{array}{l}\text { Participación a } \\
\text { nivel local }\end{array}$ & Cali \\
\hline $\begin{array}{l}\text { Evaristo } \\
\text { Priftis }\end{array}$ & $1925-27$ & Grecia & $\begin{array}{l}\text { Participación } \\
\text { a nivel local en } \\
\text { la Sociedad de } \\
\text { Obreros Libres. } \\
\text { Corresponsal de } \\
\text { La Humanidad }\end{array}$ & Neiva \\
\hline $\begin{array}{l}\text { Elías } \\
\text { Castellanos }\end{array}$ & 1925 & España & $\begin{array}{l}\text { Administrador } \\
\text { Vía Libre } \\
\text { Miembro del } \\
\text { Grupo Libertario }\end{array}$ & $\begin{array}{l}\text { Barranquilla } \\
\text { Santa } \\
\text { Marta }\end{array}$ \\
\hline $\begin{array}{l}\text { Mariano } \\
\text { Lacambra }\end{array}$ & 1925 & España & $\begin{array}{l}\text { Miembro del } \\
\text { Grupo Libertario }\end{array}$ & $\begin{array}{l}\text { Santa } \\
\text { Marta }\end{array}$ \\
\hline $\begin{array}{l}\text { Abad } \\
\text { Lacambra }\end{array}$ & 1925 & España & $\begin{array}{l}\text { Miembro del } \\
\text { Grupo Libertario }\end{array}$ & $\begin{array}{l}\text { Santa } \\
\text { Marta }\end{array}$ \\
\hline
\end{tabular}




\begin{tabular}{|c|c|c|c|c|}
\hline Nombre & Año & País & $\begin{array}{c}\text { Actividad } \\
\text { desarrollada }\end{array}$ & $\begin{array}{c}\text { Lugar } \\
\text { actividad }\end{array}$ \\
\hline $\begin{array}{l}\text { Genaro } \\
\text { Toroni }\end{array}$ & 1925 & Italia & $\begin{array}{l}\text { Miembro del } \\
\text { Grupo Libertario }\end{array}$ & $\begin{array}{l}\text { Santa } \\
\text { Marta }\end{array}$ \\
\hline $\begin{array}{l}\text { Juan } \\
\text { Candamosa }\end{array}$ & $1925-28$ & Italia & $\begin{array}{l}\text { Miembro del } \\
\text { Grupo Libertario }\end{array}$ & $\begin{array}{l}\text { Santa } \\
\text { Marta }\end{array}$ \\
\hline Juan García & $1925-27$ & España & $\begin{array}{l}\text { Intercambio con } \\
\text { grupos anarquis- } \\
\text { tas y sociedades } \\
\text { obreras, } \\
\text { delegado } \\
\text { Congreso Obrero } \\
1926 \\
\end{array}$ & Bogotá \\
\hline $\begin{array}{l}\text { Filippo } \\
\text { Colombo }\end{array}$ & $1925-27$ & Italia & $\begin{array}{l}\text { Intercambio } \\
\text { con grupos } \\
\text { anarquistas } \\
\text { y sociedades } \\
\text { obreras, } \\
\text { delegado } \\
\text { Congreso Obrero } \\
1926 \\
\end{array}$ & Bogotá \\
\hline $\begin{array}{l}\text { José } \\
\text { González } \\
\text { Arce }\end{array}$ & $1927-29$ & Bolivia & $\begin{array}{l}\text { Militancia activa } \\
\text { en el PSR }\end{array}$ & $\begin{array}{l}\text { Cali, } \\
\text { Medellín, } \\
\text { Cartagena }\end{array}$ \\
\hline $\begin{array}{l}\text { Gustav } \\
\text { Thiele }\end{array}$ & 1928 & Alemania & $\begin{array}{l}\text { Vínculos con el } \\
\text { PSR local }\end{array}$ & Moniquirá \\
\hline $\begin{array}{l}\text { Salvador de } \\
\text { la Plaza }\end{array}$ & 1928 & Venezuela & $\begin{array}{l}\text { Actividades } \\
\text { marginales en } \\
\text { asocio con el } \\
\text { PSR } \\
\end{array}$ & B/quilla \\
\hline $\begin{array}{l}\text { James } \\
\text { Harfield } \\
\text { ("Jaime } \\
\text { Nevárez") }\end{array}$ & 1928-30 & USA & $\begin{array}{l}\text { Militante PSR } \\
\text { como miembro } \\
\text { de la IC }\end{array}$ & $\begin{array}{l}\text { Diversos } \\
\text { lugares }\end{array}$ \\
\hline Jorge Vivó & 1928 & Cuba & $\begin{array}{l}\text { Militancia activa } \\
\text { en el PSR }\end{array}$ & Cali \\
\hline \multirow[t]{2}{*}{ N. Martínez } & 1928 & España & $\begin{array}{l}\text { Vínculos } \\
\text { trabajadores } \\
\text { bananeros } \\
\end{array}$ & $\begin{array}{l}\text { Sevilla, } \\
\text { Mag. }\end{array}$ \\
\hline & 1928 & Ecuador & $\begin{array}{l}\text { Líder Sindicato } \\
\text { Libertario de } \\
\text { Sastres }\end{array}$ & Barranquilla \\
\hline
\end{tabular}


Patriotismo o universalismo proletario. El lugar del mundo en el obrerismo y el socialismo colombiano, 1904-1930

\begin{tabular}{|l|c|l|l|l|}
\hline \multicolumn{1}{|c|}{ Nombre } & \multicolumn{1}{c|}{ Año } & \multicolumn{1}{c|}{ País } & $\begin{array}{c}\text { Actividad } \\
\text { desarrollada }\end{array}$ & $\begin{array}{c}\text { Lugar } \\
\text { actividad }\end{array}$ \\
\hline $\begin{array}{l}\text { Octave } \\
\text { Rabaté } \\
\text { (“Juan } \\
\text { Austine") }\end{array}$ & $1928-29$ & Francia & $\begin{array}{l}\text { Aplicación } \\
\text { directrices de } \\
\text { la IC }\end{array}$ & $\begin{array}{l}\text { Bogotá, } \\
\text { Cali, Costa } \\
\text { Atlánt. }\end{array}$ \\
\hline $\begin{array}{l}\text { Isaac } \\
\text { Rincón }\end{array}$ & $1914-29$ & Nicaragua & $\begin{array}{l}\text { Difusión } \\
\text { socialismo }\end{array}$ & Santander \\
\hline $\begin{array}{l}\text { Miguel } \\
\text { Contreras }\end{array}$ & 1928,30 & Argentina & $\begin{array}{l}\text { Tareas IC, entre } \\
\text { ellas fundación } \\
\text { Partido } \\
\text { Comunista }\end{array}$ & Bogotá \\
\hline $\begin{array}{l}\text { Carmen } \\
\text { Fortoul }\end{array}$ & 1930 & Venezuela & $\begin{array}{l}\text { Fundación } \\
\text { Partido } \\
\text { Comunista }\end{array}$ & Bogotá \\
\hline $\begin{array}{l}\text { Joseph } \\
\text { Kornfeder }\end{array}$ & 1930 & USA & Tareas de la IC & Bogotá \\
\hline
\end{tabular}

Fuentes: "Apuntes", El Artesano, diciembre 23 de 1911, Cúcuta; "La conferencia de González Blanco", La Capital, marzo 31 de 1911, Bogotá; "Cultura extrauniversitaria", El Proteccionista, abril 9 de 1911, Bogotá; "Conferencia en Zipaquirá", El Proteccionista, mayo 12 de 1911, Bogotá; República, febrero 3 de 1915, p. 2, Barranquilla; Orlando Fals Borda, Historia doble de la Costa, t. 4, pp. 140A-161A; "Expediente relacionado con la expulsión del país del extranjero Nicolás Gutarra", AGN, República, FMG, secc. $4^{\text {a }}$, t. 185, f. 327; ElEspectador, julio 10 de 1925, Bogotá, p. 1; Ignacio Torres Giraldo, Anecdotario, pp. 98-99; Carlos Cortés Vargas, Los sucesos de las bananeras, pp. 9-10, 22, 44; Miguel Urrutia, Historia del sindicalismo en Colombia, p. 129; Alfredo Gómez, Anarquismo y anarcosindicalismo en América Latina, pp. 74-76; El Tiempo, noviembre 22 de 1926, Bogotá, p. 5; AGN, República, FMG, secc. 1ª , t. 982, f. 328; AGN, República, FMG, secc. 1ª, t. 983, f. 72; Diana Lorena Piedad Jaimes, Trabajadores ferroviarios y conflicto social en Santander, p. 190; Ignacio Torres Giraldo, Los inconformes, t. 3, p. 740, t. 4, pp. 878, 1017; Klaus Meschkat y José María Rojas, Liquidando el pasado, pp. 98, 122, 141, 374, 415, 459, 574-575. 


\section{Fuentes documentales}

Álbum Rojo, 1910, Santander de Quilichao.

Archivo General de la Nación, A.G.N. República, Fondo Ministerio de Gobierno, sección 4a , t. 129, 185, 212, 230.

Archivo General de la Nación, A.G.N República, Fondo Ministerio de Gobierno, sección 1ª t. 843, 927, 982.

Chantecler, 1910, Bogotá.

El Baluarte, 1919, Girardot.

El Diario Nacional, 1923, Bogotá.

El Domingo, 1912, Bogotá.

El Espectador, 1921, 1925, Bogotá.

El Liberal, 1911, Bogotá.

El Luchador, 1919, Medellín.

El Motor, 1924, Honda.

El Obrero Colombiano, 1917, Bogotá.

El Obrero Moderno, 1913, Bucaramanga.

El Partido Obrero, 1916, Bogotá.

El Piloto, 1919, Bogotá.

El Proteccionista, 1911, Bogotá.

El Ravachol, 1910, Bogotá.

El Renacimiento, 1910, Barranquilla. 
Patriotismo o universalismo proletario. El lugar del mundo en el obrerismo y el socialismo colombiano, 1904-1930

El Símbolo, 1910, Cartagena.

El Socialista, 1928, Bogotá.

El Tiempo, 1912, 1918-19, 1922, 1924, 1926-27, Bogotá.

El Yunque, 1919, Facatativá.

Gaceta Republicana, 1919, Bogotá.

La Capital, 1911, Bogotá.

La Correspondencia, 1912, Tolú.

La Integridad Nacional, 1910, Bogotá.

La Libertad, 1909-1920, Bogotá.

La Lucha, 1920, Girardot.

La Ola Roja, 1920, Popayán.

La Opinión, 1926, Girardot.

La Razón del Obrero, 1910, Bogotá.

La República, 1925, Bogotá.

La Unión Obrera, 1911, Bucaramanga.

La Unión Obrera, 1919, Bucaramanga.

Los Principios, 1909, Bogotá.

Pensamiento y Voluntad, 1926, Bogotá.

República, 1915, Barranquilla.

Via Libre, 1925, Barranquilla. 


\section{Bibliografía}

Acelas, Julio César. "Obreros y artesanos de Bucaramanga: organización, protagonismo e ideología, 1908-1935". (Monografía Historia, Universidad Industrial de Santander Bucaramanga, 1993).

Archila, Mauricio. "La otra opinión: la prensa obrera en Colombia 1920-1934", Anuario Colombiano de Historia Social y de la Cultura, No. 13/14, 1986, Bogotá.

Archila, Mauricio. Cultura e identidad obrera. Colombia 19101945. Bogotá: Cinep, 1991.

Caballero, Manuel. La Internacional Comunista y la revolución latinoamericana, $2^{\mathrm{a}}$ ed. Editorial Nueva Sociedad, Caracas, 1978.

Cortés Vargas, Carlos. Los sucesos de las bananeras. Bogotá: Imprenta de La Luz, 1929.

Courtois, Stéphane y Lazar, Marc. Histoire du Parti communiste français, $2^{\mathrm{a}}$ ed. París: PUF, 2000.

Cuadros Caldas, Julio. Comunismo criollo y liberalismo autóctono, $3^{\mathrm{a}}$ ed. Bucaramanga: Editorial de Marco A. Gómez, 1938.

De Heredia, Francisco. "Programa del Partido Socialista". Bogotá: Editorial Santafé, 1925.

Fals Borda, Orlando. Historia doble de la Costa, t. 4. Bogotá: Carlos Valencia Editores, 1986.

Gálvez, Juan Ignacio. Dos conferencias. Organización obrera en Colombia. Quito: Casa Editorial de J. I. Gálvez, 1912.

Hart, John. El anarquismo y la clase obrera mexicana: 18601931. México: Siglo XXI Editores, 1980. 
Jaimes, Diana Lorenza Piedad. "Trabajadores ferroviarios y conflicto social en Santander (1926-1930): levantamiento de La Gómez en 1929" (monografía historia Universidad Industrial de Santander, Bucaramanga, 1995).

"La masacre de las bananeras", Teoría y práctica, No. 14, abril de 1979, Bogotá, pp. 5-29.

Martínez, Frédéric. El nacionalismo cosmopolita. Bogotá: Banco de la República, 2001.

Meschkat, Klaus y Rojas, José María (comps.), Liquidando el pasado. La izquierda en los archivos de la Unión Soviética. Bogotá: Fescol / Taurus, 2009.

Molina, Gerardo. Las ideas socialistas en Colombia, $2^{\mathrm{a}}$ ed. Bogotá: Tercer Mundo Editores, 1987.

Moscoso, Marlie. "La revolución mexicana desde la prensa colombiana" (Monografía Historia, Universidad Nacional, Medellín: 1992).

Rojas, José María. La estrategia insurreccional socialista y la estrategia de contención del conservatismo doctrinario, 2 vols. Cali: informe académico mecanografiado, 1989.

Sowell, David. "José Leocadio Camacho: Artisan, Editor, and PoliticalActivist", en The Human Tradition in Latin America: The Nineteenth Century, Judith Ewell y William H. Beezley (eds.). Wilmington - Delaware: Scholarly Resources Inc., 1989, pp. 269-279.

Torres Giraldo, Ignacio. Anecdotario. Cali: Universidad del Valle, 2004.

Torres Giraldo, Ignacio. Los inconformes. Historia de la rebeldía de las masas en Colombia, 4 vols. Bogotá: Editorial Latina, 1978. 
Torres Giraldo, Ignacio. María Cano, mujer rebelde. Bogotá: Publicaciones de La Rosca, 1972.

Uribe Márquez, Tomás. Rebeldía y acción. Al proletariado colombiano. Bogotá: Editorial Minerva, 1925.

Uribe Uribe, Rafael. "Socialismo de Estado. Conferencia leída por el General Uribe Uribe, en el Teatro Municipal de Bogotá, el 23 de octubre de 1904”. Bogotá: Ediciones Boza, s.f.

Uribe, María Tila. Los años escondidos. Sueños y rebeldías en la década del veinte. Bogotá: Cestra / Cerec, 1994.

Vega, Renán. Gente muy rebelde, 4 vols. Bogotá: Ediciones Pensamiento Crítico, 2002. 